\title{
Infrared and millimetre-wave scintillometry in the suburban environment - Part 2: Large-area sensible and latent heat fluxes
}

\author{
H. C. Ward ${ }^{1,2,3}$, J. G. Evans ${ }^{1}$, and C. S. B. Grimmond ${ }^{2,3}$ \\ ${ }^{1}$ Centre for Ecology and Hydrology, Wallingford, Oxfordshire, OX10 8BB, UK \\ ${ }^{2}$ Department of Geography, King's College London, London, WC2R 2LS, UK \\ ${ }^{3}$ Department of Meteorology, University of Reading, Reading, RG6 6BB, UK \\ Correspondence to: H. C. Ward (h.c.ward@ reading.ac.uk)
}

Received: 3 October 2014 - Published in Atmos. Meas. Tech. Discuss.: 17 November 2014

Revised: 10 February 2015 - Accepted: 28 February 2015 - Published: 20 March 2015

\begin{abstract}
A millimetre-wave scintillometer was paired with an infrared scintillometer, enabling estimation of large-area evapotranspiration across northern Swindon, a suburban area in the UK. Both sensible and latent heat fluxes can be obtained using this "two-wavelength" technique, as it is able to provide both temperature and humidity structure parameters, offering a major advantage over conventional singlewavelength scintillometry. The first paper of this two-part series presented the measurement theory and structure parameters. In this second paper, heat fluxes are obtained and analysed. These fluxes, estimated using two-wavelength scintillometry over an urban area, are the first of their kind. Source area modelling suggests the scintillometric fluxes are representative of $5-10 \mathrm{~km}^{2}$. For comparison, local-scale $(0.05-$ $0.5 \mathrm{~km}^{2}$ ) fluxes were measured by an eddy covariance station. Similar responses to seasonal changes are evident at the different scales but the energy partitioning varies between source areas. The response to moisture availability is explored using data from 2 consecutive years with contrasting rainfall patterns (2011-2012). This extensive data set offers insight into urban surface-atmosphere interactions and demonstrates the potential for two-wavelength scintillometry to deliver fluxes over mixed land cover, typically representative of an area 1-2 orders of magnitude greater than for eddy covariance measurements. Fluxes at this scale are extremely valuable for hydro-meteorological model evaluation and assessment of satellite data products.
\end{abstract}

\section{Introduction}

There is considerable demand for large-area estimates of evapotranspiration, or its energy equivalent, the latent heat flux. Observations of catchment-scale evapotranspiration are required for hydrological modelling, both to evaluate model performance and as forcing data for flood forecasting and for real-time river flow and water balance models. For rural environments knowledge of evapotranspiration is important for irrigation scheduling, crop management and crop yield prediction - applications which will become increasingly important with the demands of food and water security as the world's population continues to grow. The latent heat flux has been shown to be a significant component of the energy and water balance in urban areas, particularly for vegetated neighbourhoods (e.g. Grimmond and Oke, 1995, 2002). Accurate measurement and prediction of urban evapotranspiration is important for assessing the merits of urban design options (such as green roofs), water management schemes (e.g. irrigation bans) and strategies for sustainable urban drainage (Xu and Chen, 2005; Mitchell et al., 2008), as well as for better understanding of thermal comfort and flood risk.

As a tool for routine monitoring of heat fluxes, scintillometry offers several advantages: measurements are spatially representative, of high temporal resolution $(30 \mathrm{~min}$ or shorter) and continuous (i.e. not limited to cloud-free days as for some satellite products), with the ability to inherently cope with heterogeneity; systems are low maintenance and practical to install (e.g. Kleissl et al., 2009). Scintillometers measure the intensity of an electromagnetic beam transmitted 
through the turbulent atmosphere. The beam intensity varies in time due to diffraction by eddies of different densities, dependent on their temperature and humidity content. Changes in temperature and humidity are expressed as the temperature and humidity structure parameters, which are converted to fluxes of heat and water vapour using similarity theory. At infrared (or optical) wavelengths, temperature fluctuations dominate, so these instruments are suitable for deriving the sensible heat flux. Longer wavelengths (e.g. microwaves, radiowaves) are more sensitive to humidity fluctuations so that, in combination with infrared, both sensible and latent heat fluxes can be obtained more directly (Hill et al., 1988; Andreas, 1989); with a single infrared instrument estimating the latent heat flux relies on closure of the energy balance.

Hill et al. (1988) outlined the two-wavelength theory and demonstrated the viability of the technique by comparison with structure parameters and fluxes from other micrometeorological methods at a very homogeneous agricultural site. The technique has since been used to estimate heat fluxes over a vineyard (Green et al., 2000), pasture (Green et al., 2001), mixed agricultural landscapes (Meijninger et al., 2002a) and mixed agriculture with complex topography (Evans et al., 2010). The heavily instrumented LITFASS campaigns (Beyrich and Mengelkamp, 2006) focus on heterogeneous land cover, mainly mixed agriculture. During LITFASS-2003, heat fluxes from aggregated eddy covariance (EC) data compared with two-wavelength scintillometry estimates indicated generally good performance over the 11day measurement period (Meijninger et al., 2006). In addition, the bichromatic-correlation method was developed and tested (Beyrich et al., 2005; Lüdi et al., 2005). This extension to the two-wavelength method enables a path-averaged measurement of the temperature-humidity correlation coefficient, thus removing the need to assume its value as with the traditional two-wavelength method. In the overview paper of LITFASS-2009 (Beyrich et al., 2012) structure parameters from two example days, 12-13 July 2009, are presented. Two-wavelength scintillometry remains a specialist technique at present, as only a few instruments of longer wavelength exist, although a commercially available system has recently been developed (Hartogensis et al., 2013). A three-wavelength method has also been proposed as a solution to obtaining the combined temperature-humidity fluctuations, but would require at least three scintillometers and sensitivity analyses suggest results may not be significantly improved over the two-wavelength method (Andreas, 1990).

Single-wavelength (large aperture) scintillometry is now a fairly well-established technique deployed in a variety of locations, although its use in urban environments has only developed recently. A 3-week campaign in Marseille demonstrated good agreement between scintillometer and EC sensible heat fluxes over the "reasonably homogeneous" built surface (Lagouarde et al., 2006). A much longer campaign in Łódź looks at diurnal and seasonal variability (Zieliński et al., 2012). Results from Swindon using the single-wavelength method (i.e. infrared scintillometers only) are presented in a separate paper (Ward et al., 2014). Other urban sites include London (Gouvea and Grimmond, 2010), Toulouse (Masson et al., 2008), Nantes (Mestayer et al., 2011) and Helsinki (Wood et al., 2013). These studies are concerned with the sensible heat flux.

Here, we report on the first large-area sensible and latent heat fluxes obtained from a two-wavelength scintillometer system installed over the urban environment. Results are analysed alongside EC measurements representative of a much smaller scale. An extensive data set spanning 14 months enables the seasonal variability of the fluxes to be investigated, as well as differences between years. Following the theoretical (Sect. 2) and experimental (Sect. 3) details, the performance of the techniques is critically examined (Sect. 4.1). Three approaches are considered here: the single-wavelength, two-wavelength and bichromaticcorrelation methods. Important physical processes determining the energy partitioning are then explored using the twowavelength and EC fluxes. For each wavelength (or combination of wavelengths) the conversion of the observed refractive index structure parameters to temperature $\left(C_{T}^{2}\right)$ and humidity $\left(C_{q}^{2}\right)$ structure parameters and the temperaturehumidity cross-structure parameter $\left(C_{T q}\right)$ is described in Part 1 (Ward et al., 2015).

\section{Scintillometry theory: obtaining fluxes}

Here the goal is to relate the structure parameters of temperature and humidity from scintillometry to the surface fluxes of heat and water vapour. Briefly, the two-wavelength scintillometer system provides three refractive index structure parameters $\left(C_{n}^{2}\right)$, denoted $C_{n 1 n 1}$ from the optical scintillometer, $C_{n 2 n 2}$ from the millimetre-wave scintillometer and $C_{n 1 n 2}$ from the correlation between optical and millimetre-wave signals. Conversion to the temperature and humidity structure parameters involves either the single-wavelength, twowavelength or bichromatic-correlation method. For the twowavelength method, $C_{n 1 n 1}$ and $C_{n 2 n 2}$ are combined to give $C_{T}^{2}$ and $C_{q}^{2}$, which also requires an assumption about the temperature-humidity correlation coefficient, $r_{T q}$. The assumption used in this study is $r_{T q}= \pm 0.8$. The bichromaticcorrelation method additionally measures the cross-structure parameter $C_{n 1 n 2}$ to remove the need for the $r_{T q}$ assumption. Knowing the three refractive index structure parameters $\left(C_{n 1 n 1}, C_{n 2 n 2}, C_{n 1 n 2}\right)$ enables the three meteorological structure parameters $\left(C_{T}^{2}, C_{q}^{2}, C_{T q}\right)$ to be found. A summary is given in Fig. 1 and the reader is referred to Part 1 for full details.

The structure parameters of temperature, $T$, or specific humidity, $q$, can be related to surface fluxes using MoninObukhov similarity theory (MOST). For example (Wyngaard et al., 1971), 


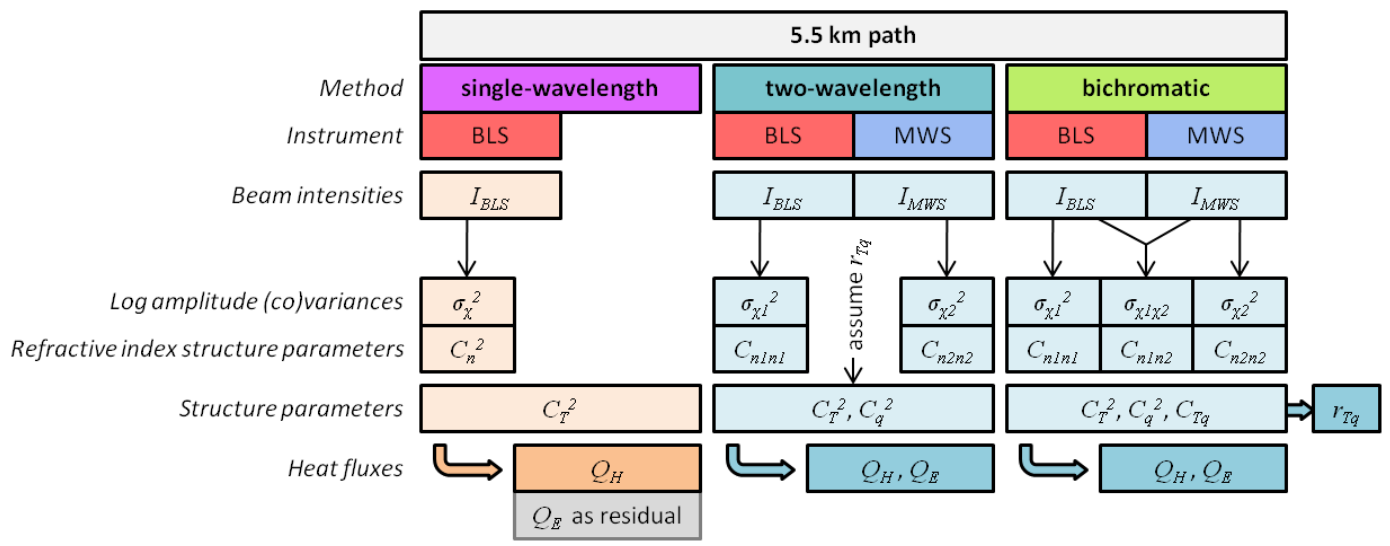

Figure 1. Methods to obtain heat fluxes from scintillometry as applicable to the experimental setup in Swindon. See Sect. 3 for details of the instrumentation, including an optical large aperture scintillometer (BLS) and a millimetre-wave scintillometer (MWS). Notation is defined in the text.

$\frac{C_{T}^{2}\left(z_{\mathrm{m}}-z_{\mathrm{d}}\right)^{2 / 3}}{T_{*}^{2}}=\frac{C_{q}^{2}\left(z_{\mathrm{m}}-z_{\mathrm{d}}\right)^{2 / 3}}{q_{*}^{2}}=f_{\mathrm{MO}}\left(\frac{z_{\mathrm{m}}-z_{\mathrm{d}}}{L_{\mathrm{Ob}}}\right)$

where $T_{*}$ and $q_{*}$ are the scaling variables of temperature and humidity respectively; $z_{\mathrm{m}}$ is the measurement height, $z_{\mathrm{d}}$ the displacement height, $L_{\mathrm{Ob}}$ the Obukhov length and $f_{\mathrm{MO}}$ is a similarity function describing the height dependence as a function of stability. Thus, scintillometry is an indirect method for obtaining fluxes. For the path-averaged quantities obtained from scintillometry, the effective height, $z_{\mathrm{ef}}$, is used in place of $\left(z_{\mathrm{m}}-z_{\mathrm{d}}\right)$ as described in Hartogensis et al. (2003). The stability parameter, $\zeta$, is defined as $\left(z_{\mathrm{m}}-z_{\mathrm{d}}\right) / L_{\mathrm{Ob}}$ for the EC station and $z_{\mathrm{ef}} / L_{\mathrm{Ob}}$ for the scintillometer system. The Obukhov length is calculated from (e.g. Green et al., 2000)

$L_{\mathrm{Ob}}=\frac{u_{*}^{2} T}{g \kappa_{\mathrm{v}} T_{*}(1+0.07 / \beta)}$,

where $g$ is the acceleration due to gravity, $\kappa_{\mathrm{v}}$ is von Kármán's constant and $\beta$ is the Bowen ratio. The required friction velocity $\left(u_{*}\right)$ input is obtained from a point measurement of wind speed and an estimate of the roughness length $\left(z_{0}\right)$ using the Businger-Dyer functions. The scaling variables, stability and effective height are determined by iteration (e.g. Moene et al., 2004).

Several forms of the similarity functions exist in the literature. Useful discussions can be found in Braam et al. (2012, 2014) and Beyrich et al. (2012) in the context of scintillometry, and in Kanda et al. (2002) for consideration of urban environments. The choice of similarity function for this data set is investigated in Appendix A. As in other scintillometry studies, identical functions for $T$ and $q$ are assumed here. The widely used forms with the constants suggested by Andreas (1988) are used,
$\begin{array}{ll}f_{\mathrm{MO}}(\zeta)=c_{T 1}\left(1-c_{T 2} \zeta\right)^{-2 / 3} & (\zeta<0), \\ f_{\mathrm{MO}}(\zeta)=c_{T 1}\left(1+c_{T 3} \zeta^{2 / 3}\right) & (\zeta>0),\end{array}$

with $c_{T 1}=4.9, c_{T 2}=6.1$ and $c_{T 3}=2.2$ (hereafter An88).

The sensible heat flux is calculated using

$Q_{\mathrm{H}}=-\rho c_{\mathrm{p}} u_{*} T_{*}$,

where $\rho$ is the density of air and $c_{\mathrm{p}}$ the specific heat capacity at constant pressure. The latent heat flux is calculated following Ward et al. (2013b):

$Q_{\mathrm{E}}=-\rho L_{\mathrm{v}} u_{*} q_{*}$,

where $L_{\mathrm{V}}$ is the latent heat of vaporisation. Equations (4) and (5) define the scaling variables. When $q_{*}$ is not known (as for the single-wavelength method), $Q_{\mathrm{E}}$ may be estimated as the residual of the surface energy balance if all other terms are known, but the complexity of energy partitioning in urban areas makes this very difficult. The urban energy balance can be written (Oke, 1987)

$Q^{*}+Q_{\mathrm{F}}=Q_{\mathrm{H}}+Q_{\mathrm{E}}+\Delta Q_{\mathrm{S}}$,

where $Q^{*}$ is the net all-wave radiation, $Q_{\mathrm{F}}$ the anthropogenic heat flux and $\Delta Q_{\mathrm{S}}$ the net storage heat flux. The Bowen ratio, $\beta$, is expressed in terms of the fluxes as $Q_{\mathrm{H}} / Q_{\mathrm{E}}$.

\section{Observational details}

A two-wavelength scintillometer system was deployed on a $5.5 \mathrm{~km}$ path over a suburban area of Swindon, UK. This system comprises an infrared scintillometer, the BLS900 (Scintec, Rottenburg, Germany), and a $94 \mathrm{GHz}$ millimetre-wave scintillometer (Evans, 2009). Near the centre of the scintillometer path an EC station was installed at a height of $12.5 \mathrm{~m}$ 
Table 1. Details of the scintillometer and eddy covariance systems. Tx denotes transmitter; Rx denotes receiver. ${ }^{*}$ The height of the scintillometer system is given as the effective height of the BLS. Values in square brackets represent the probable range of each quantity: the range in effective height represents the variation with stability; for $z_{0}$ and $z_{\mathrm{d}}$ these are based on the literature (e.g. Grimmond and Oke, 1999). See text for details of the source area estimation.

\begin{tabular}{|c|c|c|c|c|c|c|c|}
\hline \multirow[b]{2}{*}{ Instrumentation } & \multirow[b]{2}{*}{ Location } & \multirow[b]{2}{*}{$\begin{array}{l}\text { Height } \\
{[\mathrm{m}]}\end{array}$} & \multirow[b]{2}{*}{$\begin{array}{l}z_{0} \\
{[\mathrm{~m}]}\end{array}$} & \multirow[b]{2}{*}{$\begin{array}{l}z_{\mathrm{d}} \\
{[\mathrm{m}]}\end{array}$} & \multicolumn{3}{|c|}{$\begin{array}{c}\text { Approx. source area }\left[\mathrm{km}^{2}\right] \\
\text { unstable (stable) }\end{array}$} \\
\hline & & & & & $95 \%$ & $80 \%$ & $50 \%$ \\
\hline $\begin{array}{l}\text { BLS-MWS } \\
\text { scintillometer } \\
\text { system }\end{array}$ & $\begin{array}{l}51^{\circ} 36^{\prime} 33.9^{\prime \prime} \mathrm{N} 1^{\circ} 47^{\prime} 38.6^{\prime \prime} \mathrm{W}(\mathrm{Tx}) \\
51^{\circ} 33^{\prime} 38.1^{\prime \prime} \mathrm{N} 1^{\circ} 46^{\prime} 55.3^{\prime \prime} \mathrm{W}(\mathrm{Rx})\end{array}$ & $\begin{array}{l}45.0^{*} \\
{[39.0-45.0]}\end{array}$ & $\begin{array}{l}0.7 \\
{[0.5-1.1]}\end{array}$ & $\begin{array}{l}4.9 \\
{[4.4-5.4]}\end{array}$ & $\begin{array}{l}7.5 \\
(10.2)\end{array}$ & $\begin{array}{l}3.0 \\
(6.9)\end{array}$ & $\begin{array}{l}0.9 \\
(3.2)\end{array}$ \\
\hline $\begin{array}{l}\text { Eddy covariance } \\
\text { station }\end{array}$ & $51^{\circ} 35^{\prime} 4.6^{\prime \prime} \mathrm{N} 1^{\circ} 47^{\prime} 53.2^{\prime \prime} \mathrm{W}$ & 12.5 & $\begin{array}{l}0.5 \\
{[0.4-0.9]}\end{array}$ & $\begin{array}{l}3.5 \\
{[3.0-4.0]}\end{array}$ & $\begin{array}{l}0.5 \\
(0.7)\end{array}$ & $\begin{array}{l}0.06 \\
(0.1)\end{array}$ & $\begin{array}{l}0.007 \\
(0.01)\end{array}$ \\
\hline
\end{tabular}

in the garden of a residential property. The instrument locations and typical source areas of the fluxes are shown in Fig. 2.

Table 1 summarises the instrumental setup and site characteristics. The effective height of the scintillometer system is given as the effective height of the BLS according to Eq. (15) of Hartogensis et al. (2003) and includes the displacement height. A single value for the displacement height and roughness length were based on the mean height of buildings and trees $\left(z_{\mathrm{H}}\right)$ (within $500 \mathrm{~m}$ of the EC site and $1000 \mathrm{~m}$ of the scintillometer path) and the relations $z_{0}=0.1 z_{\mathrm{H}}, z_{\mathrm{d}}=0.7 z_{\mathrm{H}}$ (Garratt, 1992; Grimmond and Oke, 1999).

Source area estimation combines an analytical model (Hsieh et al., 2000) with the scintillometer path weighting (e.g. Meijninger et al., 2002b). The values in Table 1 and used for Fig. 2 are for typical atmospheric conditions: southwesterly wind $\left(225^{\circ}\right), u_{*}=0.5 \mathrm{~m} \mathrm{~s}^{-1}$, standard deviation of lateral wind $\sigma_{v}=0.9 \mathrm{~m} \mathrm{~s}^{-1}$ and $L_{\mathrm{Ob}}=-200 \mathrm{~m}(200 \mathrm{~m}$ for stable conditions).

Variation in surface cover composition with wind direction and stability is shown in Fig. 3 for typical EC and BLSMWS footprints (normalised to give a total of $100 \%$ ). The source area composition is more variable for EC than the BLS-MWS, owing to the greater spatial sampling of the BLS-MWS and the distribution of land cover surrounding the EC mast: paved areas, buildings and roads to the southwest and large gardens to the northeast. The relative contribution of vegetation to the EC source area is lowest for southwesterly winds $\left(32 \%\right.$ for $\left.225^{\circ}\right)$ and highest for northeasterly winds $\left(53 \%\right.$ for $\left.45^{\circ}\right)$. The BLS-MWS footprint always has a significant contribution from vegetation, partly due to the large nature reserve near the centre of the path (Fig. 2). For unstable conditions the BLS-MWS footprint comprises $56 \%$ vegetation cover on average. For stable conditions, the BLSMWS source area is larger and contains a greater contribution from the town centre to the south and industrial areas to the east and southwest. For northerly winds and stable conditions, the source area extends beyond suburban Swindon and

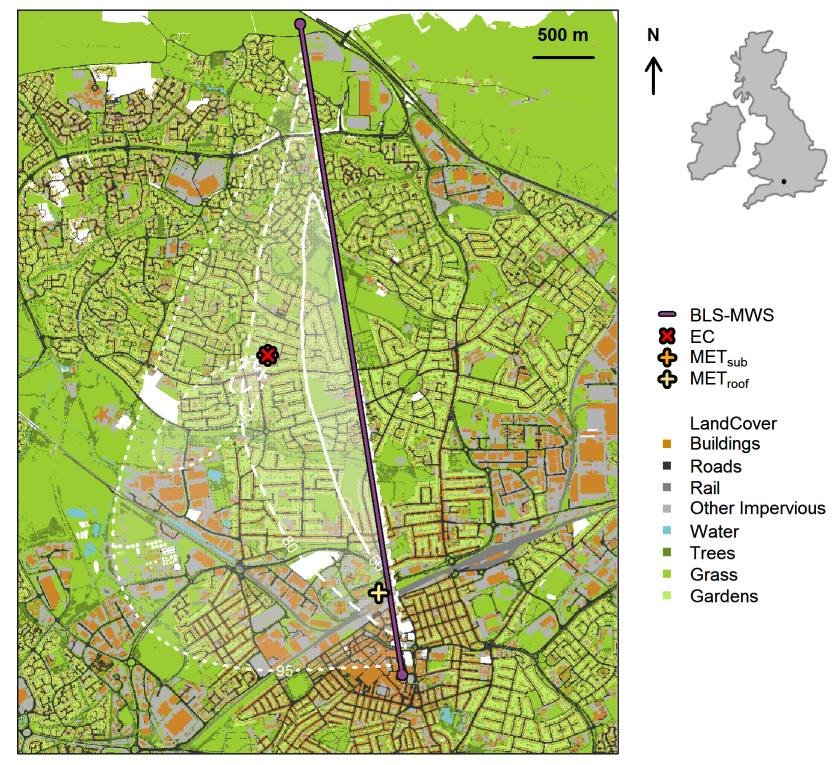

Figure 2. Land cover map of the study area showing the twowavelength scintillometer path (BLS-MWS) and locations of the eddy covariance station (EC) and two meteorological stations $\left(\mathrm{MET}_{\text {sub }}, \mathrm{MET}_{\text {roof }}\right)$. Land cover classification was based on a geodatabase (OS MasterMap $2010{ }^{\circ}$ Crown Copyright), lidar data (2007, ${ }^{\odot}$ Infoterra Ltd) and aerial photography (2009, ${ }^{\circledR}$ GeoPerspectives). Where data were unavailable, areas are left unclassified (white). Example footprints indicate the area contributing 50,80 and $95 \%$ of the observed fluxes for typical unstable atmospheric conditions and southwesterly wind (see text for details). The location of Swindon within the British Isles is shown (top right panel).

over the rural areas. At these times the footprint extends considerably beyond the edges of the land cover map (Fig. 2); thus the land cover composition (and source area size) is less reliable - an even larger contribution from vegetation is expected than suggested by Fig. 3. Note that the size of the 

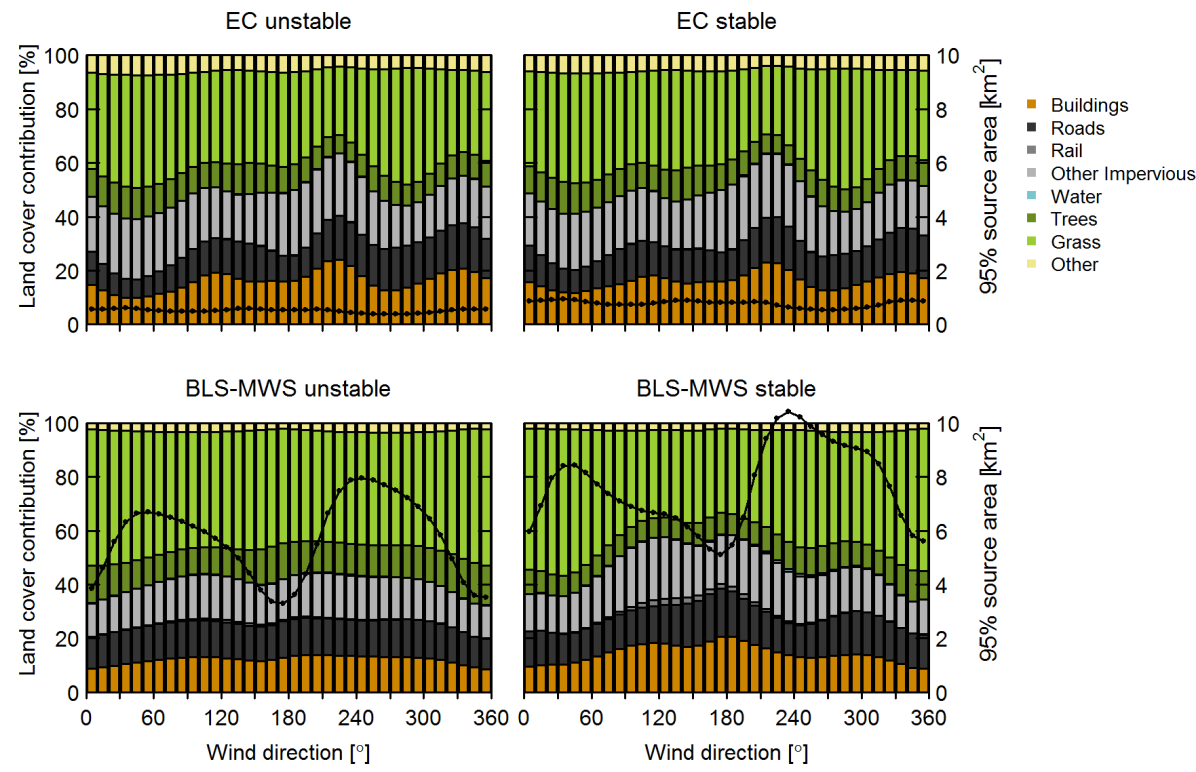

Figure 3. Contribution of land cover types to the EC and BLS-MWS source areas by wind direction for typical atmospheric conditions $\left(u_{*}=0.5 \mathrm{~m} \mathrm{~s}^{-1}, \sigma_{v}=0.9 \mathrm{~m} \mathrm{~s}^{-1}, L_{\mathrm{Ob}}= \pm 200 \mathrm{~m}\right)$. Black lines indicate the approximate size of the source area contributing $95 \%$ of the flux (right-hand axis).

source area depends on the wind direction; it is smallest when winds are near parallel to the scintillometer path.

Other meteorological instrumentation was also installed at the EC site (denoted $\mathrm{MET}_{\text {sub }}$ ). An automatic weather station (WXT 510/520, Vaisala, Finland) at a height of $10.6 \mathrm{~m}$ provides the temperature, pressure, humidity and wind speed inputs required to process the scintillometry data. A fourcomponent radiometer (NR01, Hukseflux, The Netherlands) at $10.1 \mathrm{~m}$ provides incoming and outgoing shortwave $\left(K_{\downarrow}\right.$, $\left.K_{\uparrow}\right)$ and longwave $\left(L_{\downarrow}, L_{\uparrow}\right)$ radiation and the net all-wave radiation. A tipping bucket rain gauge $(0.2 \mathrm{~mm}$ tip, Casella, Bedford, UK) is situated near the base of the EC mast. Data from a second meteorological station on a rooftop near the town centre (MET $\mathrm{M}_{\text {roof }}$, Fig. 2) were used to gap-fill $\mathrm{MET}_{\text {sub }}$ to provide a more complete set of continuous input variables (see Part 1).

The EC sensible and latent heat fluxes were calculated for every $30 \mathrm{~min}$ interval. Raw data were collected from a sonic anemometer (R3, Gill Instruments, Lymington, UK) and an open-path infrared gas analyser (IRGA) (LI-7500, LICOR Biosciences, Lincoln, USA) at $20 \mathrm{~Hz}$ (CR3000, Campbell Scientific Ltd., Loughborough, UK). Flux processing included despiking of raw data; correction for angle of attack; time-lag compensation; double co-ordinate rotation; corrections for sonic temperature (Schotanus et al., 1983), high and low frequency losses (Moncrieff et al., 1997) and gas densities (Webb et al., 1980). The open source EddyPro software (v5-00, LI-COR Biosciences) was used to implement these stages. Quality control excluded data during times of instrumental fault or when rain could adversely affect readings and data were subject to physically reasonable range checking.
More information about the EC system can be found in Ward et al. (2013a).

A CR5000 datalogger (Campbell Scientific Ltd.) sampled the BLS and MWS signal intensities at $100 \mathrm{~Hz}$. Raw signals were digitally bandpass filtered between 0.06 and $20 \mathrm{~Hz}$ for the calculation of $C_{n 2 n 2}$ and $C_{n 1 n 2}$. Quality control comprised raw data despiking, rejection of data during rain or fog, threshold checking of $C_{n}^{2}$ and removal of data strongly affected by saturation. The remaining BLS data were corrected for saturation (Clifford et al., 1974). The MWS data were well below the saturation threshold (Clifford et al., 1974), and no correction was applied to the MWS data or the BLS-MWS cross-correlation. For further discussion see Part 1.

The calculation of fluxes from scintillometry proceeds as described in Sect. 2. During daytime hours between minima in $C_{n 1 n 1}$, the similarity functions for unstable conditions were used; at other times stable conditions were assumed. The two-wavelength results were calculated assuming positive $r_{T q}$ during unstable conditions (i.e. assuming $Q_{\mathrm{H}}>0, Q_{\mathrm{E}}>0$ ) and negative $r_{T q}$ under stable conditions (i.e. assuming $Q_{\mathrm{H}}<0, Q_{\mathrm{E}}>0$ ). Clearly the two-wavelength method will suffer a positive bias in $Q_{\mathrm{E}}$ resulting from these assumptions; i.e. dewfall $\left(Q_{\mathrm{E}}<0\right)$ is never identified. The bichromatic-correlation method, in principle, provides more information than the two-wavelength method. Initially, unstable conditions during daytime and stable conditions at night are assumed. Then, for cases of observed $r_{T q}<0$ during daytime (between $C_{n 1 n 1}$ minima), $Q_{\mathrm{E}}$ is assumed to remain positive but $Q_{\mathrm{H}}$ to switch to being negative, so the stable similarity function is used. This may be expected to occur 
following rainfall when surfaces are wet. During the night it is more difficult to determine the correct stability regime, as $r_{T q}>0$ can indicate either stable conditions and dewfall $\left(Q_{\mathrm{H}}<0, Q_{\mathrm{E}}<0\right)$ or unstable conditions and evapotranspiration $\left(Q_{\mathrm{H}}>0, Q_{\mathrm{E}}>0\right)$. Because $r_{T q}$ only describes the relative sign of the fluxes, these two situations cannot be distinguished by the bichromatic-correlation method, although it does indicate the occurrence of either of the two situations. Here, nocturnal $r_{T q}>0$ is taken to indicate dewfall. A time-step of $10 \mathrm{~min}$ was used for two-wavelength $C_{T}^{2}$ and $C_{q}^{2}$, yielding $Q_{\mathrm{H}}$ and $Q_{\mathrm{E}}$ also at $10 \mathrm{~min}$. To reduce the variability of the bichromatic-correlation method (Part 1), the corresponding fluxes were calculated at $30 \mathrm{~min}$ intervals using 30 min mean $C_{T}^{2}$ and $C_{q}^{2}$. For the single-wavelength method no Bowen ratio correction has been applied.

In the following, the subscript "EC" is used to refer to quantities derived from the eddy covariance measurements and "BLS-MWS" from scintillometry. Where results have used structure parameters calculated using the single-wavelength, two-wavelength or bichromaticcorrelation methods, these are subscripted " $1 \lambda$ ", " $2 \lambda$ " and "bc", respectively. Data are presented for 14 months when all instrumentation was functioning: July-December 2011 and May-December 2012.

\section{Results and discussion}

\subsection{Comparison of methods}

Sensible and latent heat fluxes obtained from scintillometry (bichromatic-correlation and two-wavelength methods) and eddy covariance are shown in Fig. 4. The sensible heat flux calculated using the single-wavelength method is also plotted. To our knowledge Fig. 4 includes the first fluxes derived from structure parameters where the measured combined temperature-humidity fluctuations have been incorporated via the bichromatic-correlation method.

Differences in sensible heat fluxes from the three scintillometry techniques are small. The scintillometry values match the EC values reasonably well, despite the different measurement footprints. Notable differences can be seen during the early morning of 30 September 2012 when $Q_{\mathrm{H}}$ from the scintillometers is more negative than $Q_{\mathrm{H}_{-} \mathrm{EC}}$ until around 09:00 UTC. During the middle of the day on 11 May 2012 $Q_{\text {H_EC }}$ is $50-100 \mathrm{~W} \mathrm{~m}^{-2}$ larger than the scintillometry results; possibly $Q_{\text {H_BLS-MwS }}$ is limited by saturation here (see Ward et al. (2014) for discussion). Although the $Q_{\mathrm{H}}$ values are fairly similar in magnitude, $Q_{\mathrm{E}}$ from the scintillometers tends to be larger than from EC.

Differences between the bichromatic fluxes and twowavelength fluxes are mostly small, as observed $r_{T q_{-} \text {bc }}$ values are mostly similar to the assumed $r_{T q} \_2 \lambda$ values $( \pm 0.8)$. At times when measured $r_{T q}$ deviates from the assumed values, the fluxes differ accordingly. $Q_{\mathrm{E}}$ is affected more than
$Q_{\mathrm{H}}$. Comparison with $Q^{*}$ suggests that the lower bichromatic fluxes are sometimes more realistic given the available energy, e.g. on the morning of 21 August $2011\left(Q_{\mathrm{H}}\right.$ bc and $\left.Q_{\mathrm{E} \_\mathrm{bc}}\right)$ and 11 May $2012\left(Q_{\mathrm{H} \_\mathrm{bc}}\right)$. The expected diurnal cycle of $r_{T q}$ is usually observed (positive during daytime, negative at night) and generally there is good agreement between $r_{T q_{-} \mathrm{EC}}$ and $r_{T q_{-} \mathrm{bc}}$. On 21 August 2011, for example, $r_{T q}$ changes sign at the evening transition, but also changes sign again a few hours later. Both EC and bichromatic-correlation methods capture this behaviour. The EC data reveal negative $Q_{\mathrm{E}}$ as $r_{T q}$ becomes positive, indicating dewfall. The bichromatic-correlation method is also able to identify this dew event, which is ignored by the two-wavelength assumptions ( $Q_{\mathrm{E} \_2 \lambda}$ always remains positive overnight, Sect. 3). At other times, the bichromatic results appear less reasonable. Firstly, there are incidences of $\left|r_{T q_{-} \text {bc }}\right|>1$, which do not have a meaningful physical interpretation but point to measurement limitations. Secondly, large fluctuations in $r_{T q_{-} \mathrm{bc}}$ sometimes lead to sudden spikes in the fluxes. Such variability results in fluxes that are at times almost certainly unduly influenced by the performance of the method. As discussed in Part 1, the small signal-to-noise ratio of the cross-structure parameter $C_{n 1 n 2}$ and the accumulation of uncertainties in $r_{T q}$ can contribute to large errors associated with individual measurements. For this reason, structure parameters obtained via the two-wavelength method have been used to calculate the scintillometric fluxes presented below.

\subsubsection{Evapotranspiration following rainfall}

Two-wavelength scintillometry has the potential to provide fluxes directly following rainfall, when water droplets on open-path gas analyser windows may preclude $Q_{\mathrm{E}}$ measurements by eddy covariance. Note that closed-path IRGAs permit flux measurements during or soon after rainfall, but have their own issues including water droplets wetting filters and high relative humidity causing condensation in the sample tubing. Scintillometer measurements can be made as soon as the propagation path is clear following a rain shower even when the land surface (or IRGA window) has not had time to dry. The drawback is that neither $Q_{\mathrm{H}}$ nor $Q_{\mathrm{E}}$ can be reliably obtained while the scintillometer path is obstructed, whereas EC usually provides fairly continuous $Q_{\mathrm{H}}$ measurements except during heavy rainfall. Fluxes from 3 days in July 2012 are shown in Fig. 5. $Q_{\mathrm{H} \_\mathrm{EC}}$ and $Q_{\mathrm{H} \_2 \lambda}$ are closely matched and clearly respond to the energy available, primarily net all-wave radiation. Out of the $72 \mathrm{~h}$ shown, scintillometer data are available for $56.7 \mathrm{~h}, Q_{\mathrm{H} \_ \text {EC }}$ for $66.5 \mathrm{~h}$ and $Q_{\mathrm{E} \_\mathrm{EC}}$ for only $32.5 \mathrm{~h}$. Rainfall in the evening of 11 July meant the IRGA windows remained wet throughout the night. The BLS-MWS system shows an increase in $Q_{\mathrm{E}}$ after rainfall and non-zero evapotranspiration through the night $(0.6 \mathrm{~mm}$ between 21:30 and 08:00 UTC on 12 July; no $Q_{\text {E_EC }}$ data were available during this time). Very high rates of evapotranspiration can be observed when surface water is abundant 

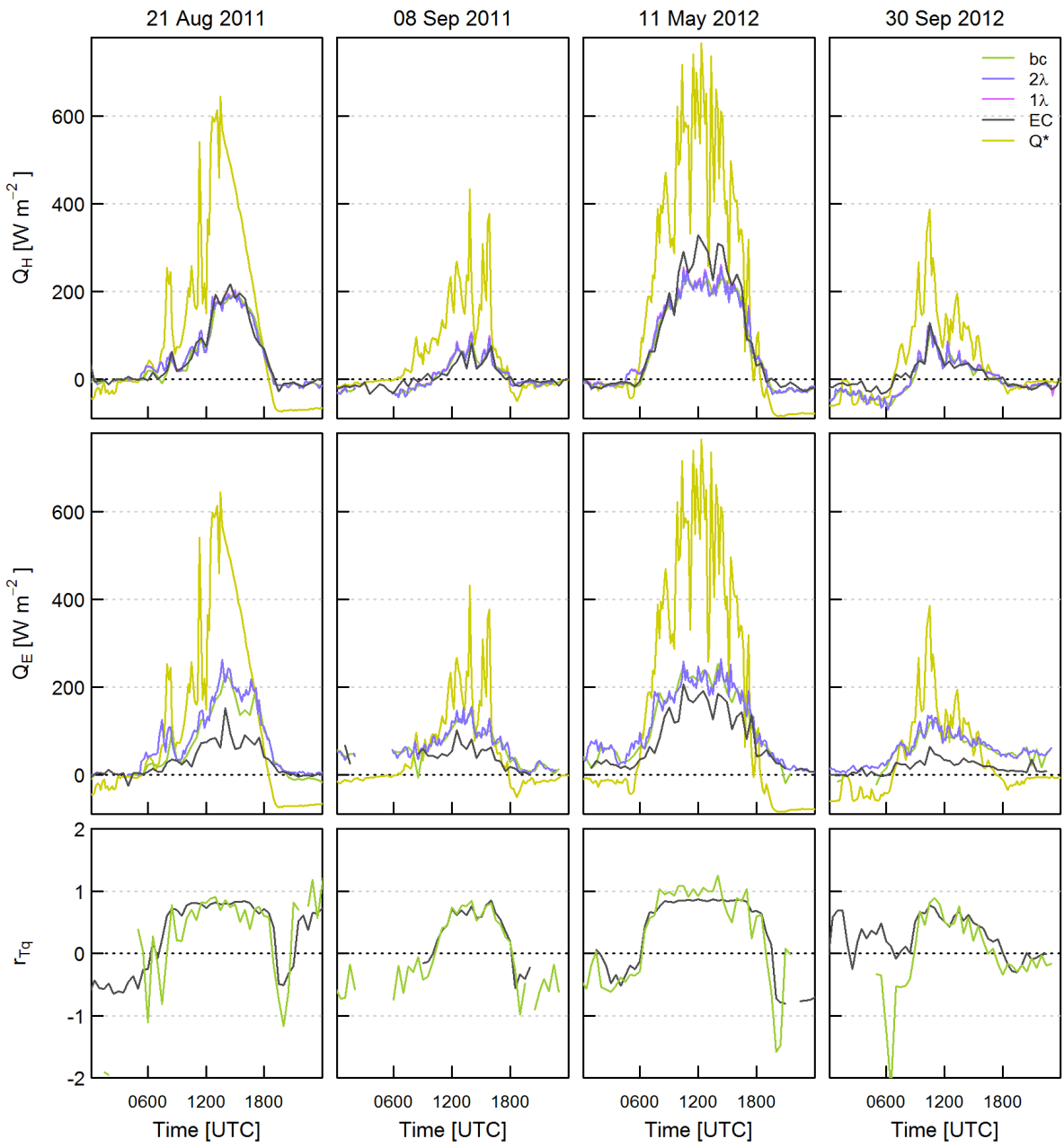

Figure 4. Sensible and latent heat fluxes and net all-wave radiation $\left(Q^{*}\right)$ and the temperature-humidity correlation coefficient for selected days. Single-wavelength and two-wavelength results are for $10 \mathrm{~min}$ intervals; EC and bichromatic statistics are at 30 min intervals (structure parameters for the same days are shown in Fig. 8 of Part 1).

and there is considerable energy input from $Q^{*}$, such as in the middle of the day on 11 July. Latent heat fluxes exceeded $500 \mathrm{~W} \mathrm{~m}^{-2}$ and the variability seen in $Q_{\mathrm{E}}$ is a response to incoming radiation. Short averaging times for the scintillometer fluxes $(10 \mathrm{~min})$ are an advantage in capturing the rapid response of the drying surface. Total evapotranspiration may be significantly underestimated by the EC method because of missing measurements following rainfall (Heusinkveld et al., 2008). Using an urban canopy model at a site on a university campus, Ramamurthy and Bou-Zeid (2014) estimated that nearly $5 \%$ of total evapotranspiration was missed due to wet IRGA windows. Two-wavelength scintillometry may provide a method to estimate fluxes that overcomes this issue.

\subsubsection{Source area characteristics}

Flux footprints are variable in time due to changing atmospheric conditions, primarily stability and wind direction (e.g. Schmid, 1994; Hsieh et al., 2000). Due to the distribution of surface cover around the EC mast (Fig. 3), differences in the carbon balance with wind direction are seen (Ward et al., 2013a). Large-scale scintillometer measurements are generally less susceptible to variation in land cover sampled - an advantage in terms of obtaining representative data sets. The land cover composition of the BLS-MWS footprint offers greater potential for transpiration than the impervious surfaces around the EC mast. Footprint differences between the systems are further enhanced considering that the EC source area is more built-up for the prevailing southwesterly wind (Sect. 3). The influence of land cover on fluxes is explored in the following case study.

Towards the end of May 2012 (after very wet and cloudy weather since early April), there was an extended period of warm and sunny weather during which vegetation quickly developed and leafed-out (22-28 May). Increased insolation on 22 May encouraged photosynthesis, $Q_{\mathrm{E}}$ increased rapidly 

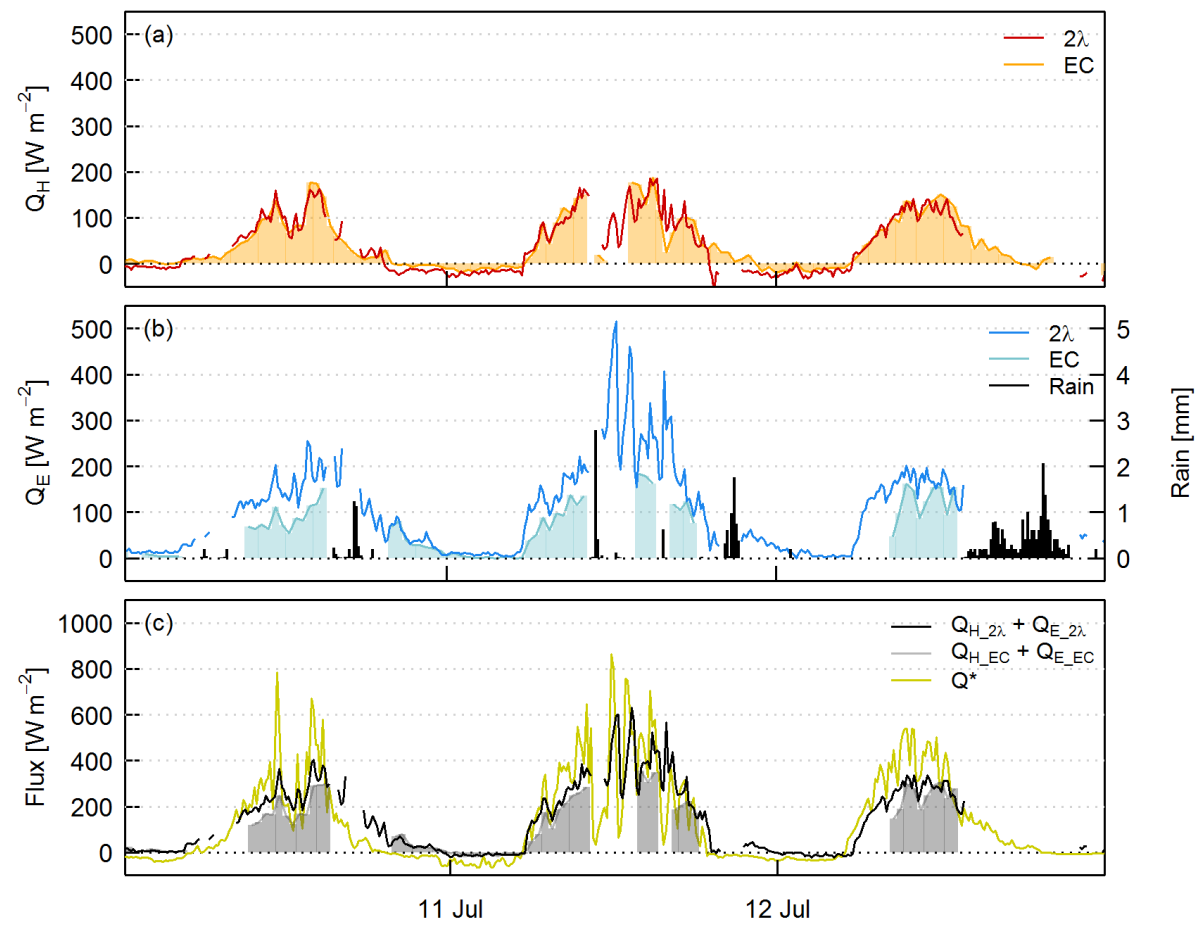

Figure 5. Response of (a) sensible and (b) latent heat fluxes to rainfall (right-hand axis) and (c) net all-wave radiation. Shading indicates availability of EC data. EC data are at $30 \mathrm{~min}$ intervals; all other data are at $10 \mathrm{~min}$ intervals.

and $\beta$ decreased as transpiration rates rose (Fig. 6). The highest rates of evapotranspiration were observed on $25-27$ May when conditions were warm and windy (reaching $25^{\circ} \mathrm{C}$ and $6 \mathrm{~m} \mathrm{~s}^{-1}$ on 25-26 May) with a high vapour pressure deficit $(20 \mathrm{hPa})$ and plenty of available energy and moisture. The EC-measured carbon dioxide flux also indicates strong photosynthetic uptake on these days (not shown). On 25-26 May winds are northeasterly and the EC source area contains a large proportion of active vegetation; more energy is directed into $Q_{\text {E_EC }}$ than $Q_{\text {H_EC. }}$. Once the wind direction becomes more southwesterly again $\beta_{\mathrm{EC}}$ increases and continues to increase as the urban surface dries out, peaking on 31 May. Once rain arrives and the wind direction changes on 1 June, $\beta_{\mathrm{EC}}$ drops again. Meanwhile, a consistently high proportion of vegetation in the scintillometer source area maintains low $\beta_{2 \lambda}$ throughout this period.

The similarity between $Q_{\mathrm{H} \_\mathrm{EC}}$ and $Q_{\mathrm{H} \_2 \lambda}$ is remarkable. $\mathrm{EC}$ and scintillometry are often in good agreement, even during night-time when both data sets have larger associated uncertainties (e.g. large negative $Q_{\mathrm{H}}$ observed on 25-26 and 26-27 May, Fig. 6b). On 23, 27 and 29 May, clouds give rise to sudden changes in $Q^{*}$. $Q_{\mathrm{H} \_\mathrm{EC}}$ rapidly adjusts, particularly the sharp peak on 29 May, while for the scintillometer system the radiation patterns are replicated to a lesser extent. This is likely due to spatial sampling. Firstly, area-averaging tends to result in smoother diurnal cycles for scintillometry fluxes than EC (Lagouarde et al., 2006; Guyot et al., 2009). Secondly, the EC system and radiometer are located on the same mast, so their footprints are located in approximately the same area, whereas the footprint of the scintillometer system is larger and in a different location. These differences are particularly relevant when considering how the surface responds to patchy cloud cover across scales of $10-100 \mathrm{~m}$. It is therefore expected that $Q^{*}$ would correlate better with $Q_{\mathrm{H} \_ \text {EC }}$ than $Q_{\mathrm{H} \_2 \lambda}$.

Despite the close agreement in $Q_{\mathrm{H}}$, the latent heat flux from the scintillometers often exceeds that from EC. Average daily evapotranspiration from the BLS-MWS is $1.5-3$ times larger than from EC (Fig. 7). Thus not only does the energy partitioning $(\beta)$ differ between EC and BLS-MWS data sets, but the sum of the turbulent fluxes $\left(Q_{\mathrm{H}}+Q_{\mathrm{E}}\right)$ is greater for the BLS-MWS system than for the EC system.

To some extent, the degree of urbanisation in the source areas could contribute to differences in $Q_{\mathrm{H}}+Q_{\mathrm{E}}$. Anthropogenic and net storage heat fluxes are non-negligible contributions to the urban energy budget (Eq. 6). Both of these terms tend to increase with urban density, as energy demand increases with population density and large thermal masses made from anthropogenic materials (e.g. buildings) effectively absorb and release heat. Therefore the EC footprint is likely associated with a slightly higher $Q_{\mathrm{F}}$ than the BLS-MWS footprint. Conversely to what is observed, this would provide more energy for $Q_{\mathrm{H}}+Q_{\mathrm{E}}$, not less. However, such differences are estimated to be small given the size of $Q_{\mathrm{F}}$ : peak values are estimated at about $10-15 \mathrm{~W} \mathrm{~m}^{-2}$ for suburban Swindon (Ward et al., 2013a) which is within 

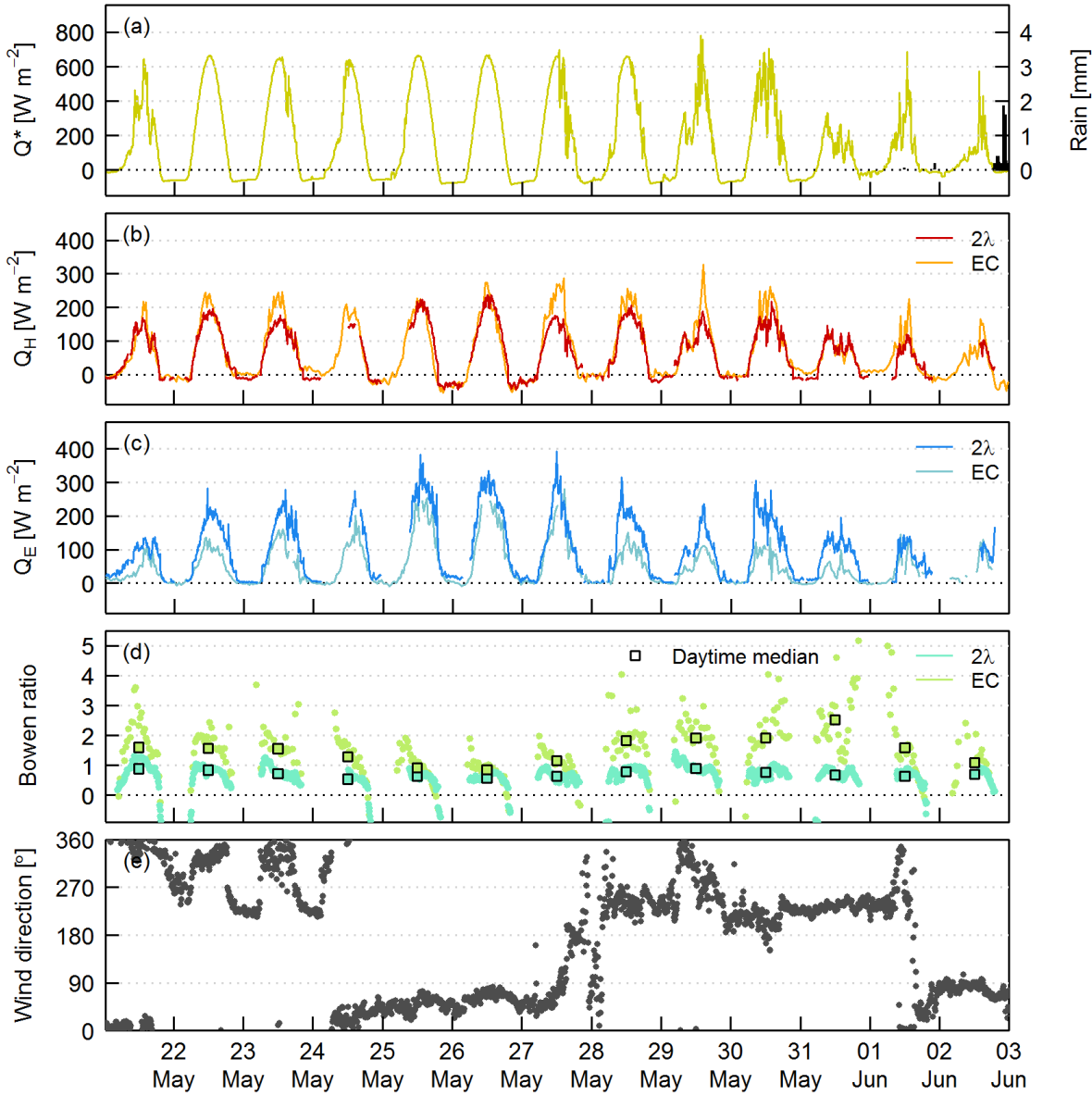

Figure 6. Energy partitioning according to eddy covariance and scintillometry during a warm, dry period in spring 2012. In (d) only daytime data are shown.
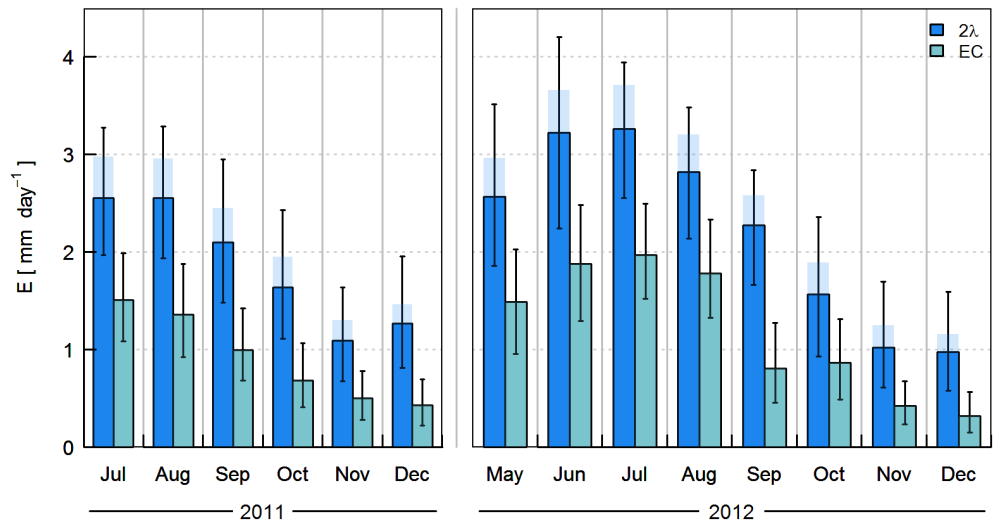

Figure 7. Average daily evapotranspiration by month: bars represent the sum over the median daily cycle of evapotranspiration for each month; error bars indicate the upper and lower quartiles; shading indicates the impact of using the De Bruin et al. (1993) similarity function.

the expected range for similar environments (e.g. Christen and Vogt, 2004; Bergeron and Strachan, 2010). The EC footprint probably has a larger associated $\Delta Q_{\mathrm{S}}$, which corresponds to smaller $Q_{\mathrm{H}}+Q_{\mathrm{E}}$, when $\Delta Q_{\mathrm{S}}>0$. Whilst $\Delta Q_{\mathrm{S}}$ may be a contributing factor to observed differences between
EC and BLS-MWS data sets, if it was the main explanation one would expect other suggestions that this is the case, for example in the shape of the diurnal cycle of $Q_{\mathrm{H}}\left(Q_{\mathrm{H} \_\mathrm{EC}}\right.$ would lag $\left.Q_{\mathrm{H}_{-} 2 \lambda}\right)$, which are not seen. There may also be differences in $Q^{*}$ between the source areas, although stud- 
ies have suggested that the radiation budget may not vary between surfaces as much as might be expected because the relevant properties (albedo and radiative temperature) tend to have compensating effects on the outgoing shortwave and longwave radiative fluxes (Schmid et al., 1991; Christen and Vogt, 2004). Nevertheless, spatial variability in cloud cover still makes it challenging to obtain $Q^{*}$ measurements representative of scintillometer source areas. Other reasons for differences between EC and scintillometry results (aside from source area characteristics) are considered in the next section.

\subsubsection{Consideration of uncertainties}

Studies that have made direct comparisons between EC and scintillometry have generally found reasonable agreement within experimental uncertainties, though two-wavelength estimates of $Q_{\mathrm{E}}$ are often quite large. Meijninger et al. (2002a) found a difference of $8 \%$ between $Q_{\mathrm{E}_{-} 2 \lambda}$ and $Q_{\mathrm{E} \_ \text {EC }}$. Meijninger et al. (2006) found $Q_{\mathrm{E} \_2 \lambda}$ (using in situ $r_{T q}$ from EC) was $26 \%$ larger than $Q_{\mathrm{E}}$ from EC data aggregated over the source area. The corresponding $Q_{\mathrm{H}_{-} 2 \lambda}$ overestimated $Q_{\mathrm{H} \_ \text {EC }}$ by $7 \%$, and for low fluxes $\left(<150 \mathrm{~W} \mathrm{~m}^{-2}\right)$ $Q_{\mathrm{H} \_2 \lambda}+Q_{\mathrm{E} \_2 \lambda}$ was larger than the estimated available energy. (Note that the scintillometry data were not processed identically in these two studies.) Underestimation of turbulent fluxes by EC may partly explain these differences; under-closure of the energy balance is widely documented and can commonly be as much as 10-20\% (Wilson et al., 2002; Frank et al., 2013). A variety of explanations have been suggested, including instrumental limitations (Kochendorfer et al., 2012), large-scale circulations (Foken, 2008) and inadequate accounting for other terms in the energy balance (Leuning et al., 2012). As these factors are unlikely to affect scintillometry in the same way (for example, scintillometers have a much larger spatial sampling volume), it should perhaps be expected that EC fluxes are smaller.

In Swindon, $Q_{\mathrm{E}}$ from the BLS-MWS is almost always higher than that from $\mathrm{EC}$, whilst $Q_{\mathrm{H}}$ is similar during the day and more negative at night (Fig. 8). Regression of 30 min $Q_{\mathrm{H}}+Q_{\mathrm{E}}$ against $Q^{*}$ yields slopes of $0.65(2 \lambda)$ and 0.59 (EC) with substantial offsets of $37 \mathrm{~W} \mathrm{~m}^{-2}(2 \lambda)$ and $15 \mathrm{~W} \mathrm{~m}^{-2}$ (EC). A small positive offset is expected given the contribution of the anthropogenic heat flux (Eq. 6; Sect. 4.1.2). For regressions of daily average $Q_{\mathrm{H}}+Q_{\mathrm{E}}$ against $Q^{*}$ (excluding days with $<50 \%$ data available), the slopes increase and offsets decrease - to 0.83 and

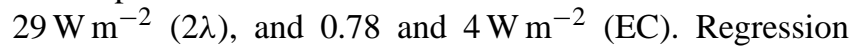
of $Q_{\mathrm{H} \_2 \lambda}+Q_{\mathrm{E} \_2 \lambda}$ with $Q_{\mathrm{H} \_\mathrm{EC}}+Q_{\mathrm{E} \_\mathrm{EC}}$ gives slopes and intercepts of 1.03 and $23 \mathrm{~W} \mathrm{~m}^{-2}(30 \mathrm{~min})$, and 0.96 and $30 \mathrm{~W} \mathrm{~m}^{-2}$ (daily average). This non-negligible offset between techniques seems to be related to overestimation of BLS-MWS fluxes by the similarity functions.

In general, there is a tendency for similarity functions to overestimate very small fluxes. Large scatter during stable and neutral times demonstrates the limitation of similarity theory scaling and cautions that flux estimates are less reliable at these times. This may partly explain the large magnitude of wintertime fluxes from scintillometry (Fig. 8a and c) and the corresponding high evapotranspiration rates for December 2011 and 2012 (Fig. 7). The general shape of the observed temperature and humidity scaling, based on EC values, is described by similarity functions given in the literature (Appendix A). Agreement is often quite good in unstable conditions (e.g. for An88 and De Bruin et al., 1993, DB93), but the fits are poorer in near-neutral and stable conditions, as the data become more scattered. For neutral stability there are differences in the behaviour of temperature and humidity. While the temperature scaling diverges, the humidity scaling tends towards an approximately constant value which appears to be larger than suggested by An88 or DB93. These features will result in overestimation of the magnitude of $Q_{\mathrm{H}}$ and $Q_{\mathrm{E}}$ under these conditions. In Fig. 7 the average daily evapotranspiration calculated using DB93 is shown (shaded) in comparison to the values derived using An88 (bars). The impact of the choice of similarity function can alter the daily evapotranspiration by $0.20-0.45 \mathrm{~mm}$, i.e. approximately $15-$ $20 \%$ or more.

Compared to the uncertainty associated with similarity functions, other uncertainties in the derivation of fluxes are mostly small. Out of the required input quantities, uncertainties in the beam height, $z_{0}$ and wind speed are most important; the long path length reduces the impact of inaccuracies in estimating its length and sensitivity to the other meteorological input variables is small (Hartogensis et al., 2003; Ward et al., 2014). Using the range of $z_{0}$ given in Table $1, Q_{\mathrm{H}}$ and $Q_{\mathrm{E}}$ would decrease by $7 \%$ or increase by $14 \%$. The displacement height is incorporated in the effective height, and as a change in $z_{\mathrm{d}}$ of $\pm 0.5 \mathrm{~m}$ is minor compared to $z_{\mathrm{ef}}$ itself, it has negligible impact $(<1 \%)$ on the fluxes. The range of $z_{\mathrm{ef}}$ given in Table 1 is for the limiting cases of free convection and near-neutral stability (according to Eqs. (13) and (14) of Hartogensis et al., 2003). Using these values of $z_{\text {ef }}$ results in fluxes that are $6 \%$ smaller or $3 \%$ larger. Fluxes calculated using the full iterative procedure to account for stability in determination of $z_{\text {ef }}$ (Sect. 2; Eq. 12, Hartogensis et al., $2003)$, yield a much smaller range of $z_{\mathrm{ef}}(42.8-43.5 \mathrm{~m})$.

Determination of wintertime and night-time fluxes presents challenges for both EC and scintillometry. The (usually) small magnitude of the fluxes (a) may be close to the detection limit of the instruments and (b) means that relative uncertainties can be large. Weak turbulence and nonstationarity violate the assumptions required for both $\mathrm{EC}$ and scintillometry measurement theory and MOST. A shallow boundary layer may mean measurements are made outside the surface layer and may no longer relate to the surface fluxes (e.g. Braam et al., 2012). However, the rough suburban surface helps to maintain turbulent mixing and there were very few occasions observed when comparisons be- 

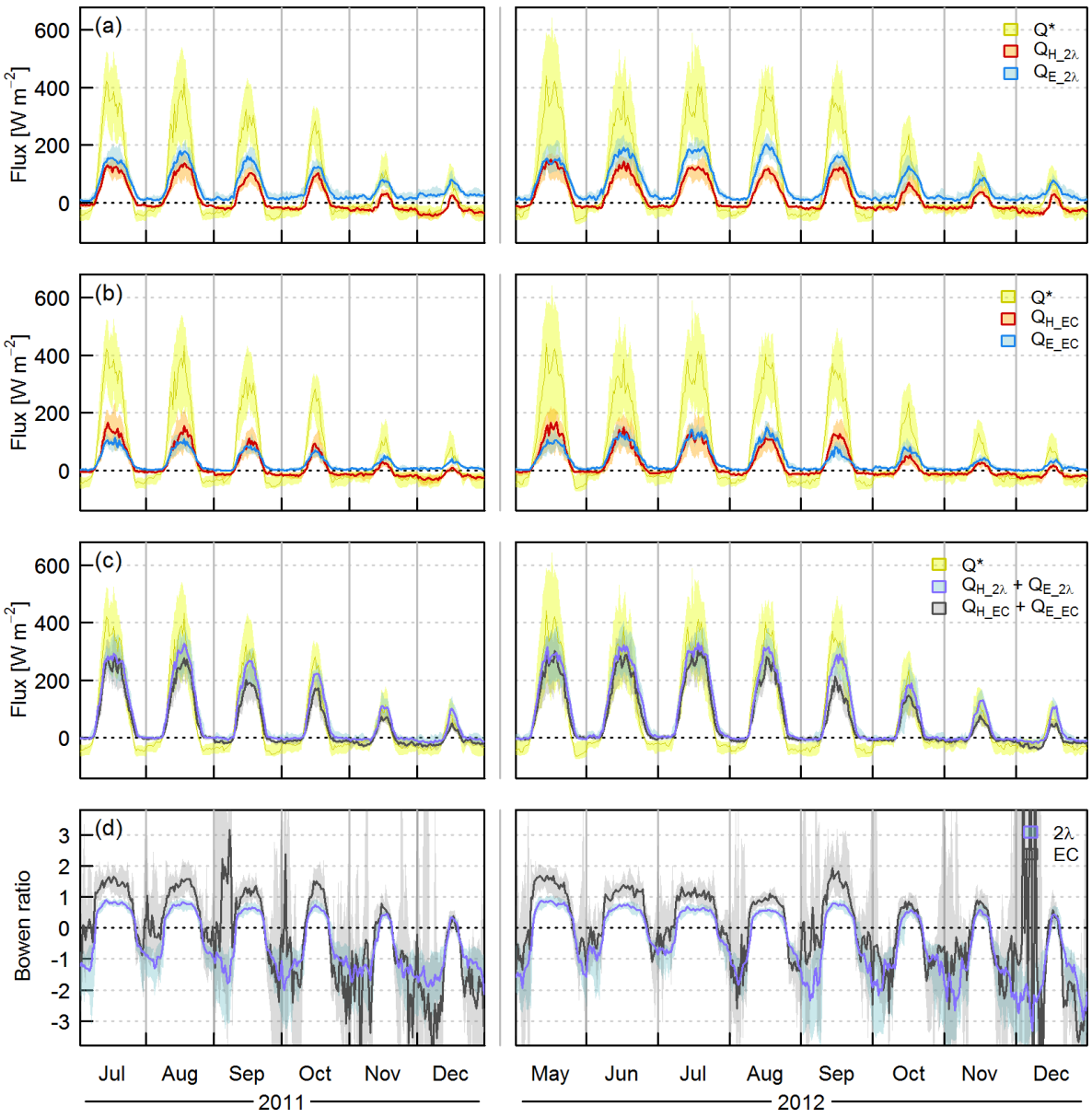

Figure 8. Monthly median diurnal cycles (lines) and inter-quartile ranges (shading) of sensible and latent heat fluxes determined using (a) two-wavelength scintillometry and (b) eddy covariance; (c) sum of the turbulent fluxes; and (d) Bowen ratio. The net all-wave radiation is also shown.

tween scintillometer and EC data suggested the scintillometers were above the surface layer.

The two-wavelength method cannot distinguish times of dewfall and "counts" these instances of negative $Q_{\mathrm{E}}$ as positive $Q_{\mathrm{E}}$ (Sect. 3). According to the EC data, dewfall $\left(Q_{\mathrm{E}}<0\right)$ was recorded for $8 \%$ of the study period, amounting to $4.9 \mathrm{~mm}$ in total. Based on this, the total evapotranspiration from the two-wavelength method may be overestimated by $\approx 10 \mathrm{~mm}$ for the whole study period. When there is heavy dewfall, however, this will often settle on the IRGA windows leading to those data being rejected, so the EC data are also expected to underestimate dewfall. An advantage of the bichromatic-correlation method is that the relative sign of the fluxes is given by $r_{T q_{-} \text {bc }}$, so that positive $r_{T q}$ during nighttime implies either $Q_{\mathrm{H}}>0, Q_{\mathrm{E}}>0$ or $Q_{\mathrm{H}}<0, Q_{\mathrm{E}}<0$.

Reduced sensitivity of the MWS around the region of minimum $C_{n 2 n 2}$ at $\beta \approx 2-3$ (Leijnse et al., 2007; Ward et al., $2013 \mathrm{~b}$ ) may also introduce a bias towards larger $Q_{\mathrm{E}}$. As discussed in Part 1, the instrumental noise floor and experimental limitations are thought to widen the region of reduced sensitivity beyond the theoretical prediction of the position of the minimum. The two-wavelength method tends to give Bowen ratios less than about 1.3. The bichromatic results suggest higher $\beta$ for about $3 \%$ of data. Although this represents a small proportion of the total data set, it could have a more substantial effect in drier conditions and may restrict the ability of two-wavelength data sets to capture changing energy partitioning as conditions increase above $\beta \approx 1.3$. It is likely that the bichromatic-correlation results are also somewhat affected by problematic $C_{n 2 n 2}$.

In summary, many of the issues affecting EC and scintillometry techniques lead to underestimated EC fluxes and overestimated scintillometry fluxes, more so for $Q_{\mathrm{E}}$ than $Q_{\mathrm{H}}$. Under-closure of the energy balance and rejection of $Q_{\mathrm{E}}$ when IRGA windows are wet result in underestimated EC fluxes (except when dewfall wets the IRGA windows and it is $Q_{\mathrm{E}}<0$ that is not measured). Two-wavelength scintillometry: (a) is able to capture large $Q_{\mathrm{E}}$ following rain; (b) suffers a bias to "count" $Q_{\mathrm{E}}<0$ (dewfall) as $Q_{\mathrm{E}}>0$; (c) relies on MOST to obtain fluxes, the limitations of which are 
thought to cause overestimation of the magnitudes of the fluxes; and (d) has limited sensitivity at moderate $\beta$ which probably leads to overestimates of $Q_{\mathrm{E}}$. Furthermore, in this setup, the source area composition also favours lower $\beta$ for the BLS-MWS. On the other hand, saturation causes underestimation of $Q_{\mathrm{H}}$ from scintillometry. Analysis of results from both techniques enables investigation into the limitations of each and provides a more complete picture of the behaviour of the environment. In the next sections, seasonal behaviour of the energy partitioning is analysed and results are set in context against other studies.

\subsection{Analysis of seasonal patterns}

Seasonal trends and substantial inter-annual variability are evident in the Swindon fluxes (Fig. 8). Average annual rainfall for southern England is $780 \mathrm{~mm}$ (1971-2000 normal, Met Office, 2013). Rainfall was below average in 2011 with an annual total of $530 \mathrm{~mm}$, and above average in 2012 $(1020 \mathrm{~mm})$, with over $900 \mathrm{~mm}$ between April and December 2012. Contrasts in water availability are reflected in the energy partitioning: $\beta$ is significantly smaller in 2012 than 2011. September 2012 deviates from the general trend of decreasing $\beta$ from summer to winter. EC averages for this month are less representative than for other months due to lower data availability, but both data sets suggest a larger $\beta$ than might be expected. This can mainly be attributed to a lack of freely available surface water and near-surface soil moisture, and fairly sunny weather during the first half of the month. By 23 September near-surface soil moisture had reached its lowest value for the period studied in 2012 (data not shown). The effect of dry impervious surfaces on the September 2012 EC observations is further enhanced due to predominantly southwesterly winds, which kept the footprint over the least vegetated areas (Sect. 3). Across the data set as a whole, the variability in daytime energy partitioning (i.e. $\beta$ ) is smaller for the BLS-MWS than EC (e.g. Figs. 6d and 8d).

\subsection{Comparison with other sites}

The Swindon results are in good agreement with the North American studies of Grimmond and Oke (1995), in that frequent rainfall during summer reduces the expected Bowen ratio from $1.0-1.5$ to $0.8-1.0$. The observed inter-annual variation highlights the advantage of multi-year data sets to obtain representative data, both in terms of assessing the climatology of a region and for selecting appropriate parameters for modelling studies. The UK climate, with frequent rainfall, means evapotranspiration continues from wet surfaces and pervious areas all year round, resulting in negative $Q_{\mathrm{H}}$ for much of the day if energy is limited. Similar energy partitioning has been noted at other suburban sites (e.g. Goldbach and Kuttler, 2013) in contrast to city centre studies where typically the water availability is reduced and the energy input is supplemented by a larger anthropogenic compo- nent (Kotthaus and Grimmond, 2014). Zieliński et al. (2012) present several months of $Q_{H}$ data from scintillometry in Łódź. While the broad seasonal trends observed are similar to those in Swindon, $Q_{\mathrm{H}}$ is larger, particularly in wintertime, which is not surprising given the higher density of buildings at their city centre site (Fortuniak et al., 2013).

The BLS-MWS provides measurements that are representative of a considerable area of suburban Swindon. These results suggest that vegetated suburban areas are able to support high rates of evapotranspiration $\left(\approx 3 \mathrm{~mm} \mathrm{day}^{-1}\right)$. For comparison, summertime daily evapotranspiration rates from UK woodlands are around 4-5 $\mathrm{mm} \mathrm{day}^{-1}$ (Roberts et al., 2005; Thomas et al., 2011). Evapotranspiration rates from residential and recreational areas in suburban MinneapolisSaint Paul, Minnesota are around $3 \mathrm{~mm} \mathrm{day}^{-1}$ in summer (Peters et al., 2011), comparable to the BLS-MWS results shown here, but near zero in winter (conditions are much colder and drier). The Swindon results are thus comparable to other published findings, but to obtain concurrent $Q_{\mathrm{H}}$ and $Q_{\mathrm{E}}$ at this scale is rare.

Low $\beta$ from the BLS-MWS system is similar to other highly vegetated sites, such as Kansas City, Missouri (58\% vegetation cover) - the observed daytime Bowen ratio of 0.47 for the August study period (Balogun et al., 2009) is one of the lowest among urban campaigns. For Swindon, average $\beta_{2 \lambda}$ is $0.5-0.6$ around midday in August 2012, but larger in $2011(\approx 0.8)$; daytime averages are smaller due to the shape of the diurnal cycle (Fig. 8d). In Kansas City, as for many of the North American studies (Grimmond and Oke, 2002), automated irrigation supplements water availability, particularly those with warm, dry summers. However the wet weather in Swindon during summer 2012 was accompanied by reduced insolation, limiting evapotranspiration despite abundant moisture (June 2012 was particularly cloudy). During winter $\beta_{\mathrm{EC}}$ and $\beta_{2 \lambda}$ are more similar than during summer, as there is less contrast between vegetated and nonvegetated surfaces compared to when plants are actively transpiring (Offerle et al., 2006). The need to incorporate seasonality into model parameterisations is discussed in Loridan and Grimmond (2012) and Best and Grimmond (2013).

Observations of decreasing $\beta$ with increasing vegetation fraction are mostly based on summertime observations (Grimmond and Oke, 2002; Christen and Vogt, 2004). Average daytime $\beta$ for summer and winter are plotted for Swindon and other sites in the literature in Fig. 9. Despite considerable scatter, clearly $\beta$ decreases as the vegetation fraction increases. Notably high $\beta$ at the rural site in Melbourne is attributed to drought conditions (Coutts et al., 2007). Values for winter months are more scattered and have a larger spread. This may be partly due to the shorter day length during winter - i.e. mean daytime $\beta$ contains a wider range of values (Fig. 8d), but it also reflects the changing role of vegetation depending on whether transpiration is occurring. For both Swindon and Montreal, where there are data for more than one summer and winter season, there is often a substan- 


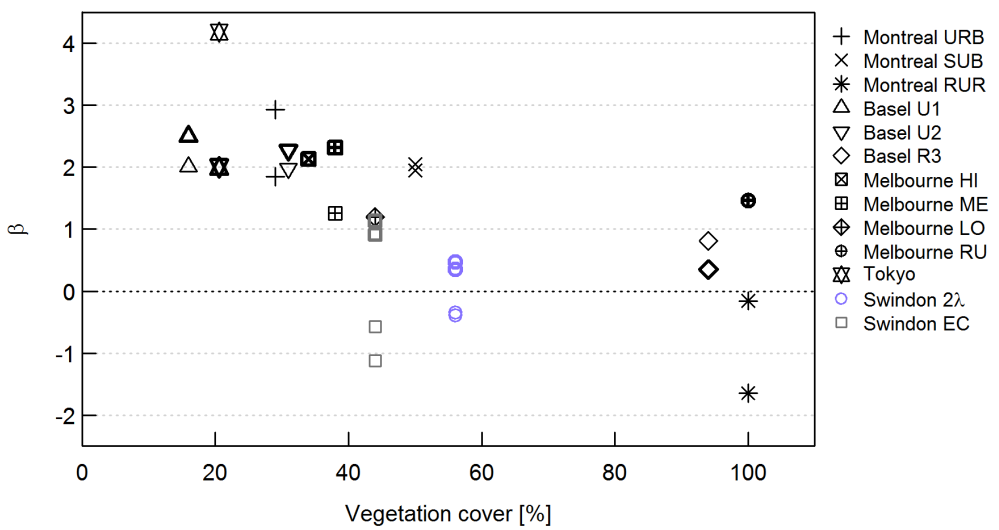

Figure 9. Observed daytime Bowen ratios for summer (bold) and winter months versus plan area vegetation cover at sites in Montreal (Bergeron and Strachan, 2010), Basel (Christen and Vogt, 2004), Melbourne (Coutts et al., 2007), Tokyo (Moriwaki and Kanda, 2004) and Swindon (this study). See references for details of the sites.

tial difference between values in different years, again highlighting the importance of long-term observations.

\section{Conclusions}

The first observations of large-area heat fluxes using the two-wavelength scintillometry technique are presented for the urban environment. Higher evapotranspiration rates (and lower $\beta$ ) from the BLS-MWS (1-3 mm day ${ }^{-1}$ on average) compared with the EC measurements $\left(0.5-2 \mathrm{~mm} \mathrm{day}^{-1}\right)$ are partly attributed to the greater proportion of vegetation typically within the BLS-MWS source area. In winter, vegetation plays a smaller role ( $\beta$ is more similar between BLSMWS and EC data sets) and the available energy is a crucial factor so $Q_{\mathrm{H}}$ is often negative as a consequence of energy being directed mainly into $Q_{\mathrm{E}}$. However, a number of methodological aspects also suggest estimates of $Q_{\mathrm{E}}$ and $Q_{\mathrm{H}}+Q_{\mathrm{E}}$ from the scintillometer system may exceed those from EC. In addition to differences associated with source areas, the following issues require further exploration: selection and applicability of MOST scaling functions, especially for neutral and stable conditions; difference in energy balance closure between scintillometry and EC; and limitations of two-wavelength scintillometer systems (e.g. bias in the two-wavelength method when dewfall occurs) and better appreciation of their performance under a range of conditions (e.g. Bowen ratio). Deployment of an MWS in urban areas with a smaller proportion of vegetation, or during drier periods, may be less successful due to the reduced sensitivity at moderate $\beta$. Improvements to MOST (or an alternative solution) should be a main focus of future work, as the conversion of structure parameters to fluxes is accompanied by substantial uncertainties, especially for humidity. With the technology applied it appears the bichromatic-correlation method does not provide a full solution to the limitations of the two-wavelength method. Nevertheless, information on path-averaged temperature-humidity correlation can be used to inform data processing and aid interpretation of results. The performance of both methods should be more closely examined and current understanding must be tested experimentally.

Since scintillometer data are already spatially integrated over a large area, changes in source area with meteorological conditions tend to make less of an impact on the average composition of the footprint. This offers significant advantages when using long-term data sets to parameterise or test models. Furthermore, direct integration of large-area observations into modelling studies may facilitate either assimilation of input data or evaluation of outputs, as most models will not account for the effects of footprint differences on collected data. Transforming local-scale measurements to representative values at the scale of model grids or satellite pixels is non-trivial over heterogeneous surfaces. For example, evapotranspiration from urban greenspace can be significantly enhanced by warm surroundings (Spronken-Smith et al., 2000; Moriwaki and Kanda, 2004). Hence flux measurements over large areas are required for development and evaluation of algorithms to move between scales. The contrasting conditions between the two summer-to-winter periods studied here highlight the importance of making long-term observations in order to capture seasonal and inter-annual variability.

Field campaigns to compare different instruments and techniques, further supported by modelling studies, such as the LITFASS (Beyrich and Mengelkamp, 2006) or BUBBLE (Rotach et al., 2005) experiments, are necessary both to learn more about the advantages and shortcomings of current techniques and also to develop a more thorough understanding of boundary layer dynamics and surface-atmosphere interactions. 


\section{Appendix A: Choice of a suitable similarity function}

Here, EC data are used to assess suitable similarity functions for Swindon. Dimensionless quantities formed from the structure parameters of temperature and humidity $\left(f_{\mathrm{MO}-\mathrm{T}}\right.$, $f_{\mathrm{MO} \_\mathrm{q}}$ ) were examined and compared to functions from the literature (Fig. A1). On the whole, the observed scaling with stability follows a similar form to the range of functions given in the literature. For temperature and humidity, $f_{\mathrm{MO}}$ increases with decreasing instability then starts to flatten out around $\zeta \approx-0.03$ as neutral conditions are approached. Humidity scaling becomes approximately constant and independent of stability in neutral and stable conditions. For unstable to near-neutral conditions An88 and DB93 describe the behaviour fairly well. DB93 seems to best capture the observed behaviour with stability but the resulting fluxes are larger than reasonably expected, sometimes unfeasibly so compared to the energy available, and larger than the fluxes measured directly with the conventional EC method (fluxes directly obtained from EC can be compared to fluxes calculated via structure parameters and MOST scaling). Under stable conditions the scatter is much greater.

Instead of approaching a constant value as predicted by most of the functions in the literature, $f_{\mathrm{MO}-\mathrm{T}}$ diverges at neutral conditions, becoming very large. Similar behaviour has been observed at a rooftop site in Basel (Roth et al., 2006), and for the normalised standard deviation of temperature (Fortuniak et al., 2013; Nordbo et al., 2013). It occurs as $T_{*}$ becomes very small to compensate for large $u_{*}$ to maintain a small heat flux (Eq. 4) as neutrality is approached, and thus is a limitation of scaling in this way. Over smoother surfaces this effect may be observed less frequently as $u_{*}$ is smaller so $T_{*}$ can be larger for a given $Q_{\mathrm{H}}$. Using functions of a conventional form (Eqs. 3a and b), such as those of An88 and DB93, can therefore considerably overestimate $Q_{\mathrm{H}}$ in neutral conditions $\left(f_{\mathrm{MO} \mathrm{T}}\right.$ is too small so the $T_{*}$ obtained is too large) and means $Q_{\mathrm{H}}$ values close to zero are underrepresented or simply not obtained. Using the function fitted directly to the Swindon EC data improves estimation of these smaller $Q_{\mathrm{H}}$ values. The observational fits have the conventional functional form in unstable and stable conditions, plus two extra terms to account for the divergence towards neutral conditions:

$$
\begin{aligned}
f_{\mathrm{MO}}(\zeta) & =\frac{C_{T}^{2}\left(z_{\mathrm{m}}-z_{\mathrm{d}}\right)^{2 / 3}}{T_{*}^{2}}=4.84(1-11.6 \zeta)^{-2 / 3} \\
& +0.00024 \zeta^{-1}-0.001133 \zeta^{-2} \quad(\zeta<0) \\
f_{\mathrm{MO}}(\zeta) & =\frac{C_{T}^{2}\left(z_{\mathrm{m}}-z_{\mathrm{d}}\right)^{2 / 3}}{T_{*}^{2}}=3.54\left(1+2.23 \zeta^{2 / 3}\right) \\
& +0.00010 \zeta^{-1}+0.021083 \zeta^{-2} \quad(\zeta>0) .
\end{aligned}
$$

However, the fit to temperature does not represent the humidity scaling well.

Since most of the widely used functions in the literature do not capture this trend (possibly due to a lack of neutral data in these studies), $Q_{\mathrm{H}}$ derived using similarity theory tends to be biased towards larger values under near-neutral conditions. Although absolute errors are usually small (a few $\mathrm{W} \mathrm{m}^{-2}$ ) so too is the size of $Q_{\mathrm{H}}$ and the frequency of data between -10 and $10 \mathrm{~W} \mathrm{~m}^{-2}$ is significantly underrepresented compared to $Q_{\mathrm{H}}$ obtained from EC directly. For example, where $Q_{\mathrm{H}}$ changes sign the similarity functions (An88, DB93 and TG92; Thiermann and Grassl, 1992) result in lower values during stable conditions and higher values during unstable conditions giving a steeper change of stability overall (Fig. A1e).

Appreciable differences in the fluxes can arise depending on the similarity function used: An88 and DB93 tend to yield higher fluxes than TG92 by about $10-15 \%$ on average, with better agreement under unstable conditions. Although the fitted function performs much better under near-neutral conditions for $Q_{\mathrm{H}}$, the overall agreement is not much better than for An88 or DB93 and the performance under near-neutral conditions is worse for $Q_{\mathrm{E}}$. Given that the observed divergence is thought to be a limitation of the conventional scaling technique, we therefore decided against using the experimental fit to derive the scintillometer fluxes. Instead, An88 scaling is used for both $T$ and $q$, which closely matches the shape of the observed scaling and does not produce as significant an overestimation as DB93. 

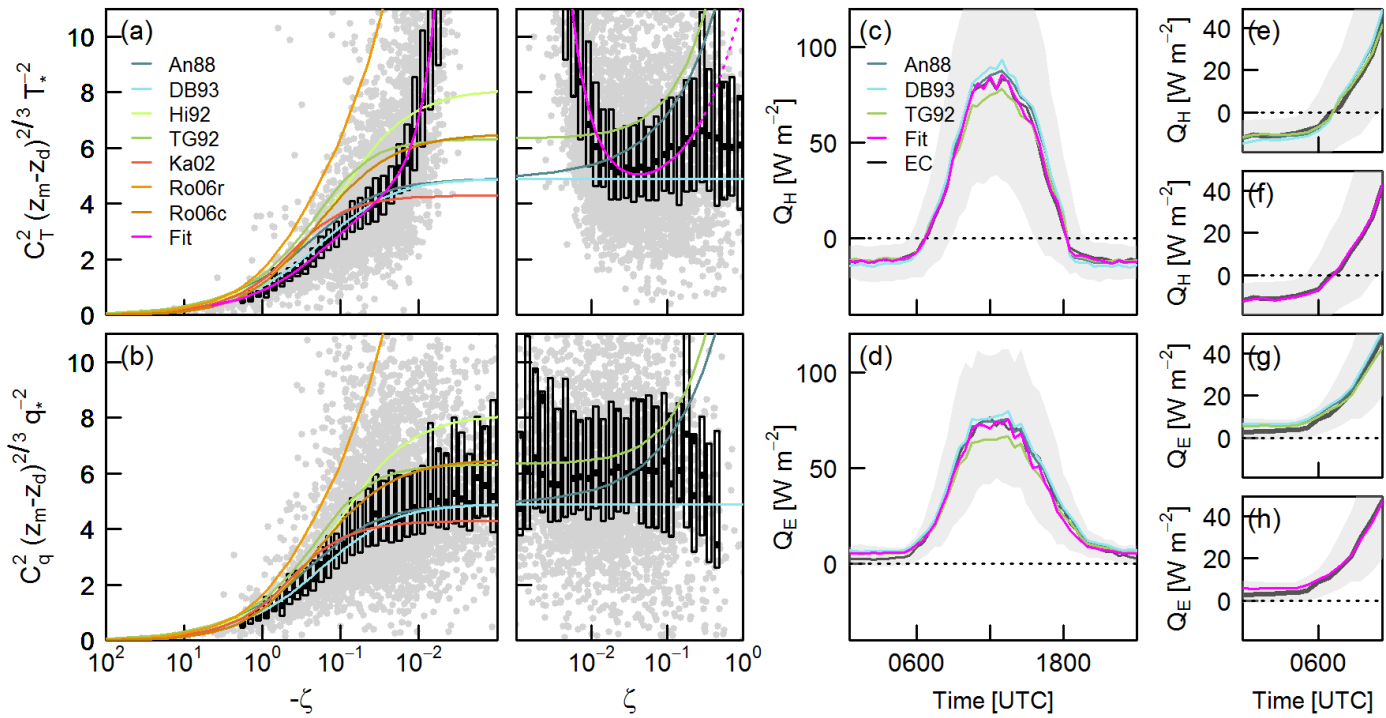

Figure A1. Comparison between EC data and similarity functions from the literature: An88 (Andreas, 1988), DB93 (De Bruin et al., 1993), Hi92 (Hill et al., 1992), TG92 (Thiermann and Grassl, 1992), Ka02 (Kanda et al., 2002) and Ro06 (Roth et al., 2006) fits to rooftop (r) and canyon (c) data sets. Box plots (a, b) indicate median and inter-quartile range (IQR) binned by stability. A fit to the Swindon data $\left(\left|Q_{\mathrm{H}}\right|>5 \mathrm{~W} \mathrm{~m}^{-2},\left|Q_{\mathrm{E}}\right|>5 \mathrm{~W} \mathrm{~m}^{-2}\right)$ is also shown for temperature (a). Median diurnal cycle of (c) $Q_{\mathrm{H}}$ and (d) $Q_{\mathrm{E}}$ for all available data as measured directly by EC (IQR shaded) and as calculated via structure parameters using the similarity functions indicated. The morning transition is magnified in (e)-(h); the fitted function is used in (f, $\mathbf{h})$. 
Acknowledgements. We wish to thank the residents of Swindon who kindly gave permission for equipment to be installed on their property. This work was funded by the Natural Environment Research Council, UK.

Edited by: F. S. Marzano

\section{References}

Andreas, E. L.: Estimating $\mathrm{C}_{n}^{2}$ over snow and sea ice from meteorological data, J. Opt. Soc. Am., 5, 481-495, 1988.

Andreas, E. L.: Two-wavelength method of measuring pathaveraged turbulent surface heat fluxes, J. Atmos. Ocean. Tech., 6, 280-292, 1989.

Andreas, E. L.: Three-wavelength method of measuring pathaveraged turbulent heat fluxes, J. Atmos. Ocean. Tech., 7, 801814, 1990.

Balogun, A., Adegoke, J., Vezhapparambu, S., Mauder, M., McFadden, J., and Gallo, K.: Surface energy balance measurements above an exurban residential neighbourhood of Kansas City, Missouri, Bound.-Lay. Meteorol., 133, 299-321, doi:10.1007/s10546-009-9421-3, 2009.

Bergeron, O. and Strachan, I. B.: Wintertime radiation and energy budget along an urbanization gradient in Montreal, Canada, Int. J. Climatol., 32, 137-152, doi:10.1002/joc.2246, 2010.

Best, M. J. and Grimmond, C. S. B.: Analysis of the seasonal cycle within the first international urban land-surface model comparison, Bound.-Lay. Meteorol., 146, 421-446, doi:10.1007/s10546012-9769-7, 2013.

Beyrich, F. and Mengelkamp, H. T.: Evaporation over a heterogeneous land surface: EVA_GRIPS and the LITFASS-2003 experiment - an overview, Bound.-Lay. Meteorol., 121, 5-32, doi:10.1007/s10546-006-9079-z, 2006.

Beyrich, F., Kouznetsov, R. D., Leps, J. P., Lüdi, A., Meijninger, W. M. L., and Weisensee, U.: Structure parameters for temperature and humidity from simultaneous eddy-covariance and scintillometer measurements, Meteorol. Z., 14, 641-649, doi:10.1127/0941-2948/2005/0064, 2005.

Beyrich, F., Bange, J., Hartogensis, O., Raasch, S., Braam, M., van Dinther, D., Gräf, D., van Kesteren, B., van den Kroonenberg, A., Maronga, B., Martin, S., and Moene, A.: Towards a Validation of Scintillometer Measurements: The LITFASS-2009 Experiment, Bound.-Lay. Meteorol., 144, 83-112, doi:10.1007/s10546-0129715-8, 2012.

Braam, M., Bosveld, F., and Moene, A.: On Monin-Obukhov Scaling in and Above the Atmospheric Surface Layer: The Complexities of Elevated Scintillometer Measurements, Bound.-Lay. Meteorol., 144, 157-177, doi:10.1007/s10546-012-9716-7, 2012.

Braam, M., Moene, A., Beyrich, F., and Holtslag, A. M.: Similarity Relations for $C_{T}^{2}$ in the Unstable Atmospheric Surface Layer: Dependence on Regression Approach, Observation Height and Stability Range, Bound.-Lay. Meteorol., 153, 63-87, doi:10.1007/s10546-014-9938-y, 2014.

Christen, A. and Vogt, R.: Energy and radiation balance of a central European city, Int. J. Climatol., 24, 1395-1421, doi:10.1002/joc.1074, 2004.
Clifford, S. F., Ochs, G. R., and Lawrence, R. S.: Saturation of optical scintillation by strong turbulence, J. Opt. Soc. Am., 64, 148154, 1974.

Coutts, A. M., Beringer, J., and Tapper, N. J.: Impact of increasing urban density on local climate: Spatial and temporal variations in the surface energy balance in Melbourne, Australia, J. Appl. Meteorol. Clim., 46, 477-493, doi:10.1175/jam2462.1, 2007.

De Bruin, H. A. R., Kohsiek, W., and Van den Hurk, B. J. J. M.: A verification of some methods to determine the fluxes of momentum, sensible heat, and water-vapour using standarddeviation and structure parameter of scalar meteorological quantities, Bound.-Lay. Meteorol. 63, 231-257, 1993.

Evans, J. G.: Long-Path Scintillometry over Complex Terrain to Determine Areal-Averaged Sensible and Latent Heat Fluxes, PhD Thesis, Soil Science Department, the University of Reading, Reading, UK, 181 pp., 2009.

Evans, J. G., McNeil, D. D., Finch, J. F., Murray, T., Harding, R. J., and Verhoef, A.: Evaporation Measurements at Kilometre Scales Determined Using Two-wavelength Scintillometry. BHS Third International Symposium, Role of Hydrology in Managing Consequences of a Changing Global Environment Newcastle University, 19-23 July 2010, Newcastle upon Tyne, UK, 2010.

Foken, T.: The energy balance closure problem: An overview, Ecol. Appl., 18, 1351-1367, 2008.

Fortuniak, K., Pawlak, W., and Siedlecki, M.: Integral Turbulence Statistics Over a Central European City Centre, Bound.-Lay. Meteorol., 146, 257-276, doi:10.1007/s10546-012-9762-1, 2013.

Frank, J. M., Massman, W. J., and Ewers, B. E.: Underestimates of sensible heat flux due to vertical velocity measurement errors in non-orthogonal sonic anemometers, Agr. Forest Meteorol., 171, 72-81, 2013.

Garratt, J. R.: The Atmospheric Boundary Layer, Cambridge University Press, Cambridge, UK, 316 pp., 1992.

Goldbach, A. and Kuttler, W.: Quantification of turbulent heat fluxes for adaptation strategies within urban planning, Int. J. Climatol., 33, 143-159, doi:10.1002/joc.3437, 2013.

Gouvea, M. L. and Grimmond, C. S. B.: Spatially integrated measurements of sensible heat flux using scintillometry, Ninth Symposium on the Urban Environment, 2-6 August 2010, Keystone, Colorado, 2010.

Green, A. E., Green, S. R., Astill, M. S., and Caspari, H. W.: Estimating latent heat flux from a vineyard using scintillometry, Terr. Atmos. Ocean. Sci., 11, 525-542, 2000.

Green, A. E., Astill, M. S., McAneney, K. J., and Nieveen, J. P.: Path-averaged surface fluxes determined from infrared and microwave scintillometers, Agr. Forest Meteorol., 109, 233-247, 2001.

Grimmond, C. S. B. and Oke, T. R.: Comparison of Heat Fluxes from Summertime Observations in the Suburbs of Four North American Cities, J. Appl. Meteorol., 34, 873-889, doi:10.1175/1520-0450(1995)034<0873:COHFFS >2.0.CO;2, 1995.

Grimmond, C. S. B. and Oke, T. R.: Aerodynamic properties of urban areas derived from analysis of surface form, J. Appl. Meteorol., 38, 1262-1292, 1999.

Grimmond, C. S. B. and Oke, T. R.: Turbulent heat fluxes in urban areas: Observations and a local-scale urban meteorological parameterization scheme (LUMPS), J. Appl. Meteorol., 41, 792810, 2002. 
Guyot, A., Cohard, J.-M., Anquetin, S., Galle, S., and Lloyd, C. R.: Combined analysis of energy and water balances to estimate latent heat flux of a sudanian small catchment, J. Hydrol., 375, 227-240, 2009

Hartogensis, O. K., Watts, C. J., Rodriguez, J. C., and De Bruin, H. A. R.: Derivation of an effective height for scintillometers: La Poza experiment in Northwest Mexico, J. Hydrometerol., 4, 915-928, 2003.

Hartogensis, O. K., Czekala, H., Philipp, M., Rose, T., Watts, C., and Cesar Rodriguez, J.: New developments in optical micro-wave scintillometer systems, Tübingen Atmospheric Physics Symposium "Scintillometers and Applications", 7-9 October 2013, Tübingen, Germany, 2013.

Heusinkveld, B. G., Jacobs, A. F. G., and Holtslag, A. A. M.: Effect of open-path gas analyzer wetness on eddy covariance flux measurements: A proposed solution, Agr. Forest Meteorol., 148, 1563-1573, doi:10.1016/j.agrformet.2008.05.010, 2008.

Hill, R. J., Bohlander, R. A., Clifford, S. F., McMillan, R. W., Priestly, J. T., and Schoenfeld, W. P.: Turbulence-induced millimeter-wave scintillation compared with micrometeorological measurements, IEEE T. Geosci. Remote, 26, 330-342, 1988.

Hill, R. J., Ochs, G. R., and Wilson, J. J.: Measuring surface-layer fluxes of heat and momentum using optical scintillation, Bound.Lay. Meteorol., 58, 391-408, doi:10.1007/bf00120239, 1992.

Hsieh, C. I., Katul, G., and Chi, T.: An approximate analytical model for footprint estimation of scalar fluxes in thermally stratified atmospheric flows, Adv. Water Resour., 23, 765-772, 2000.

Kanda, M., Moriwaki, R., Roth, M., and Oke, T.: Area-averaged sensible heat flux and a new method to determine zero-plane displacement length over an urban surface using scintillometry, Bound.-Lay. Meteorol., 105, 177-193, 2002.

Kleissl, J., Hong, S. H., and Hendrickx, J. M. H.: New Mexico scintillometer network supporting remote sensing and hydrologic and meteorological models, B. Am. Meteorol. Soc., 90, 207-218, doi:10.1175/2008bams2480.1, 2009.

Kochendorfer, J., Meyers, T., Frank, J., Massman, W., and Heuer, M.: How Well Can We Measure the Vertical Wind Speed? Implications for Fluxes of Energy and Mass, Bound.-Lay. Meteorol., 145, 383-398, doi:10.1007/s10546-012-9738-1, 2012.

Kotthaus, S. and Grimmond, C. S. B.: Energy exchange in a dense urban environment - Part I: temporal variability of long-term observations in central London, Urban Climate, 10, 261-280, doi:10.1016/j.uclim.2013.10.002, 2014

Lagouarde, J. P., Irvine, M., Bonnefond, J. M., Grimmond, C. S. B., Long, N., Oke, T. R., Salmond, J. A., and Offerle, B.: Monitoring the sensible heat flux over urban areas using large aperture scintillometry: Case study of Marseille city during the ESCOMPTE experiment, Bound.-Lay. Meteorol., 118, 449-476, doi:10.1007/s10546-005-9001-0, 2006.

Leijnse, H., Uijlenhoet, R., and Stricker, J. N. M.: Hydrometeorological application of a microwave link: 1. Evaporation, Water Resour. Res., 43, W04416, doi:10.1029/2006wr004988, 2007.

Leuning, R., van Gorsel, E., Massman, W. J., and Isaac, P. R.: Reflections on the surface energy imbalance problem, Agr. Forest. Meteorol., 156, 65-74, 2012.

Loridan, T. and Grimmond, C. S. B.: Characterization of Energy Flux Partitioning in Urban Environments: Links with Surface Seasonal Properties, J. Appl. Meteorol. Clim., 51, 219-241, doi:10.1175/jamc-d-11-038.1, 2012.
Lüdi, A., Beyrich, F., and Matzler, C.: Determination of the turbulent temperature-humidity correlation from scintillometric measurements, Bound.-Lay. Meteorol., 117, 525-550, doi:10.1007/s10546-005-1751-1, 2005.

Masson, V., Gomes, L., Pigeon, G., Liousse, C., Pont, V., Lagouarde, J. P., Voogt, J., Salmond, J., Oke, T. R., Hidalgo, J., Legain, D., Garrouste, O., Lac, C., Connan, O., Briottet, X., Lachérade, S., and Tulet, P.: The Canopy and Aerosol Particles Interactions in TOulouse Urban Layer (CAPITOUL) experiment, Meteorol. Atmos. Phys., 102, 135-157, doi:10.1007/s00703008-0289-4, 2008.

Meijninger, W. M. L., Green, A. E., Hartogensis, O. K., Kohsiek, W., Hoedjes, J. C. B., Zuurbier, R. M., and De Bruin, H. A. R.: Determination of area-averaged water vapour fluxes with large aperture and radio wave scintillometers over a heterogeneous surface - Flevoland field experiment, Bound.-Lay. Meteorol., 105, 63-83, 2002a.

Meijninger, W. M. L., Hartogensis, O. K., Kohsiek, W., Hoedjes, J. C. B., Zuurbier, R. M., and De Bruin, H. A. R.: Determination of area-averaged sensible heat fluxes with a large aperture scintillometer over a heterogeneous surface - Flevoland field experiment, Bound.-Lay. Meteorol., 105, 37-62, 2002b.

Meijninger, W. M. L., Beyrich, F., Lüdi, A., Kohsiek, W., and De Bruin, H. A. R.: Scintillometer-based turbulent fluxes of sensible and latent heat over a heterogeneous land surface - A contribution to LITFASS-2003, Bound.-Lay. Meteorol., 121, 89-110, doi:10.1007/s10546-005-9022-8, 2006.

Mestayer, P., Bagga, I., Calmet, I., Fontanilles, G., Gaudin, D., Lee, J. H., Piquet, T., Rosant, J.-M., Chancibault, K., Lebouc, L., Letellier, L., Mosini, M.-L., Rodriguez, F., Rouaud, J.-M., Sabre, M., Tétard, Y., Brut, A., Selves, J.-L., Solignac, P.-A., Brunet, Y., Dayau, S., Irvine, M., Lagouarde, J.-P., Kassouk, Z., Launeau, P., Connan, O., Defenouillère, P., Goriaux, M., Hébert, D., Letellier, B., Mario, D., Najjar, G., Nerry, F., Quentin, C., Biron, R., Cohard, J.-M., Galvez, J., and Klein, P.: The FluxSAP 2010 hydroclimatological experimental campaign over an heterogeneous urban area, 11th EMS Annual Meeting, 12-16 September 2011, Berlin, Germany, 2011.

Met Office: Climate averages (1971-2000), retrieved: 29 March 2013 from: http://www.metoffice.gov.uk/climate, 2013.

Mitchell, V. G., Cleugh, H. A., Grimmond, C. S. B., and Xu, J.: Linking urban water balance and energy balance models to analyse urban design options, Hydrol. Process., 22, 2891-2900, doi:10.1002/hyp.6868, 2008.

Moene, A. F., Meijninger, W. M. L., Hartogensis, O. K., Kohsiek, W., and De Bruin, H. A. R.: A review of the relationships describing the signal of a Large Aperture Scintillometer, Internal report 2004/2, Meteorology and Air Quality Group, Wageningen University, Wageningen, the Netherlands, 40 pp., 2004.

Moncrieff, J. B., Massheder, J. M., de Bruin, H., Elbers, J., Friborg, T., Heusinkveld, B., Kabat, P., Scott, S., Soegaard, H., and Verhoef, A.: A system to measure surface fluxes of momentum, sensible heat, water vapour and carbon dioxide, J. Hydrol., 188-199, 589-611, 1997.

Moriwaki, R. and Kanda, M.: Seasonal and diurnal fluxes of radiation, heat, water vapor, and carbon dioxide over a suburban area, J. Appl. Meteorol., 43, 1700-1710, 2004. 
Nordbo, A., Järvi, L., Haapanala, S., Moilanen, J., and Vesala, T.: Intra-City Variation in Urban Morphology and Turbulence Structure in Helsinki, Finland, Bound.-Lay. Meteorol., 146, 469-496, doi:10.1007/s10546-012-9773-y, 2013.

Offerle, B., Grimmond, C. S. B., Fortuniak, K., and Pawlak, W.: Intraurban differences of surface energy fluxes in a central European city, J. Appl. Meteorol. Clim., 45, 125-136, 2006.

Oke, T. R.: Boundary Layer Climates, Routledge, Taylor and Francis Group, London, UK, 435 pp., 1987.

Peters, E. B., Hiller, R. V., and McFadden, J. P.: Seasonal contributions of vegetation types to suburban evapotranspiration, J. Geophys. Res., 116, G01003, doi:10.1029/2010jg001463, 2011.

Ramamurthy, P. and Bou-Zeid, E.: Contribution of impervious surfaces to urban evaporation, Water Resour. Res., 50, 2889-2902, doi:10.1002/2013WR013909, 2014.

Roberts, J., Rosier, P., and Smith, D. M.: The impact of broadleaved woodland on water resources in lowland UK: II. Evaporation estimates from sensible heat flux measurements over beech woodland and grass on chalk sites in Hampshire, Hydrol. Earth Syst. Sci., 9, 607-613, doi:10.5194/hess-9-607-2005, 2005.

Rotach, M. W., Vogt, R., Bernhofer, C., Batchvarova, E., Christen, A., Clappier, A., Feddersen, B., Gryning, S. E., Martucci, G., Mayer, H., Mitev, V., Oke, T. R., Parlow, E., Richner, H., Roth, M., Roulet, Y. A., Ruffieux, D., Salmond, J. A., Schatzmann, M., and Voogt, J. A.: BUBBLE - an Urban Boundary Layer Meteorology Project, Theor. Appl. Climatol., 81, 231-261, doi:10.1007/s00704-004-0117-9, 2005.

Roth, M., Salmond, J. A., and Satyanarayana, A. N. V.: Methodological considerations regarding the measurement of turbulent fluxes in the urban roughness sublayer: The role of scintillometery, Bound.-Lay. Meteorol., 121, 351-375, doi:10.1007/s10546006-9074-4, 2006.

Schmid, H. P.: Source areas for scalars and scalar fluxes, Bound.Lay. Meteorol., 67, 293-318, doi:10.1007/bf00713146, 1994.

Schmid, H. P., Cleugh, H. A., Grimmond, C. S. B., and Oke, T. R.: Spatial variability of energy fluxes in suburban terrain, Bound.Lay. Meteorol., 54, 249-276, doi:10.1007/bf00183956, 1991.

Schotanus, P., Nieuwstadt, F. T. M., and Bruin, H. A. R.: Temperature measurement with a sonic anemometer and its application to heat and moisture fluxes, Bound.-Lay. Meteorol., 26, 81-93, doi:10.1007/bf00164332, 1983.

Spronken-Smith, R. A., Oke, T. R., and Lowry, W. P.: Advection and the surface energy balance across an irrigated urban park, Int. J. Climatol., 20, 1033-1047, 2000.

Thiermann, V. and Grassl, H.: The measurement of turbulent surface-layer fluxes by use of bichromatic scintillation, Bound.Lay. Meteorol., 58, 367-389, 1992.
Thomas, M. V., Malhi, Y., Fenn, K. M., Fisher, J. B., Morecroft, M. D., Lloyd, C. R., Taylor, M. E., and McNeil, D. D.: Carbon dioxide fluxes over an ancient broadleaved deciduous woodland in southern England, Biogeosciences, 8, 1595-1613, doi:10.5194/bg-8-1595-2011, 2011.

Ward, H. C., Evans, J. G., and Grimmond, C. S. B.: Multi-season eddy covariance observations of energy, water and carbon fluxes over a suburban area in Swindon, UK, Atmos. Chem. Phys., 13, 4645-4666, doi:10.5194/acp-13-4645-2013, 2013 a.

Ward, H. C., Evans, J. G., Hartogensis, O. K., Moene, A. F., De Bruin, H. A. R., and Grimmond, C. S. B.: A critical revision of the estimation of the latent heat flux from two-wavelength scintillometry, Q. J. Roy. Meteorol. Soc., 139, 1912-1922, doi:10.1002/qj.2076, 2013b.

Ward, H. C., Evans, J. G., and Grimmond, C. S. B.: Multi-scale sensible heat fluxes in the urban environment from large aperture scintillometry and eddy covariance, Bound.-Lay. Meteorol., 152, 65-89, doi:10.1007/s10546-014-9916-4, 2014.

Ward, H. C., Evans, J. G., Grimmond, C. S. B., and Bradford, J.: Infrared and millimetre-wave scintillometry in the suburban environment - Part 1: Structure parameters, Atmos. Meas. Tech., 8, 1385-1405, doi:10.5194/amt-8-1385-2015, 2015.

Webb, E. K., Pearman, G. I., and Leuning, R.: Correction of flux measurements for density effects due to heat and water-vapor transfer, Q. J. Roy. Meteorol. Soc., 106, 85-100, 1980.

Wilson, K., Goldstein, A., Falge, E., Aubinet, M., Baldocchi, D., Berbigier, P., Bernhofer, C., Ceulemans, R., Dolman, H., Field, C., Grelle, A., Ibrom, A., Law, B. E., Kowalski, A., Meyers, T., Moncrieff, J., Monson, R., Oechel, W., Tenhunen, J., Valentini, R., and Verma, S.: Energy balance closure at FLUXNET sites, Agr. Forest Meteorol., 113, 223-243, 2002.

Wood, C. R., Kouznetsov, R. D., Gierens, R., Nordbo, A., Järvi, L., Kallistratova, M. A., and Kukkonen, J.: On the Temperature Structure Parameter and Sensible Heat Flux over Helsinki from Sonic Anemometry and Scintillometry, J. Atmos. Ocean. Tech., 30, 1604-1615, doi:10.1175/JTECH-D-12-00209.1, 2013.

Wyngaard, J. C., Izumi, Y., and Collins, J. S. A.: Behavior of the Refractive-Index-Structure Parameter near the Ground, J. Opt. Soc. Am., 61, 1646-1650, 1971.

$\mathrm{Xu}, \mathrm{C}$. Y. and Chen, D.: Comparison of seven models for estimation of evapotranspiration and groundwater recharge using lysimeter measurement data in Germany, Hydrol. Process., 19, 3717-3734, doi:10.1002/hyp.5853, 2005.

Zieliński, M., Fortuniak, K., and Pawlak, W.: Turbulent sensible heat flux in Łódź obtained from scintillometer measurements - comparison of free and mix algorithms, Contemp. Trends Geosci., 1, 109-117, 2012. 